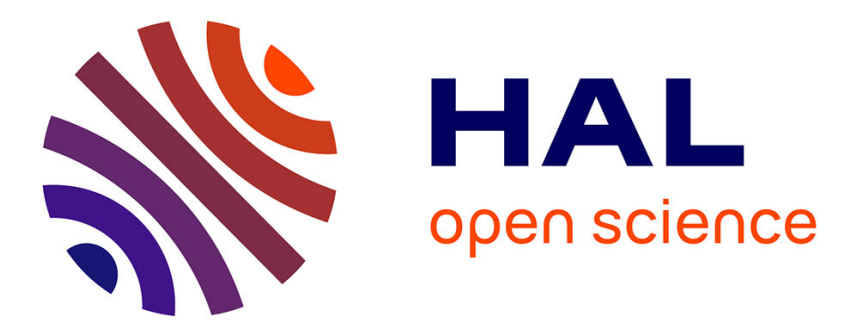

\title{
On preheating and dilution effects in non-premixed jet flame stabilization
}

\author{
Sylvain Lamige, Jiesheng Min, Cédric Galizzi, Frédéric André, Françoise \\ Baillot, Dany Escudié, Kevin Lyons
}

\section{- To cite this version:}

Sylvain Lamige, Jiesheng Min, Cédric Galizzi, Frédéric André, Françoise Baillot, et al.. On preheating and dilution effects in non-premixed jet flame stabilization. Combustion and Flame, 2013, 160 (6), pp.1102-1111. 10.1016/j.combustflame.2013.01.026 . hal-00870465

\section{HAL Id: hal-00870465 https://hal.science/hal-00870465}

Submitted on 22 Nov 2013

HAL is a multi-disciplinary open access archive for the deposit and dissemination of scientific research documents, whether they are published or not. The documents may come from teaching and research institutions in France or abroad, or from public or private research centers.
L'archive ouverte pluridisciplinaire HAL, est destinée au dépôt et à la diffusion de documents scientifiques de niveau recherche, publiés ou non, émanant des établissements d'enseignement et de recherche français ou étrangers, des laboratoires publics ou privés. 


\title{
On preheating and dilution effects in non-premixed jet flame stabilization
}

\author{
Sylvain Lamige ${ }^{\mathrm{a}, 1}$, Jiesheng Min ${ }^{\mathrm{b}}$, Cédric Galizzi ${ }^{\mathrm{a}}$, Frédéric André ${ }^{\mathrm{a}}$, Françoise Baillot ${ }^{\mathrm{b}}$, \\ Dany Escudié a ${ }^{\text {, Kevin M. Lyons }}{ }^{\text {a, c }}$ \\ a Université de Lyon, CNRS, INSA-Lyon, CETHIL, UMR5008, F-69621, Villeurbanne, France

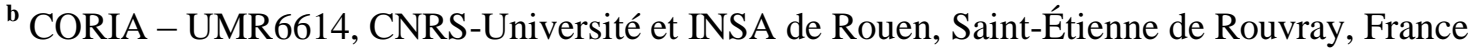 \\ ${ }^{c}$ North Carolina State University, Dept. of Mechanical and Aerospace Engineering, Raleigh, NC \\ 27695-7910 USA
}

\section{Abstract:}

The impact of preheating and dilution on methane/air non-premixed flame stability are studied experimentally. Six preheating levels are considered for initial reactant temperature between $295 \mathrm{~K}$ and $850 \mathrm{~K}$ in a round jet configuration. Four diluent gases are added on the air-side, either $\mathrm{CO}_{2}, \mathrm{~N}_{2}, \mathrm{Ar}$ or a $\left(\mathrm{CO}_{2}+\mathrm{Ar}\right)$ mixture having the same molar heat capacity as $\mathrm{N}_{2}$. For undiluted flames, jet transition velocities between attached and lifted states are investigated depending on initial reactant temperature. The hysteresis zone defined by these stability limits is shifted towards higher jet velocities with preheating. Whereas jet and coflow temperatures were identical in similar previous experiments, the present work allows examination of the thermal effects from either fuel or oxidizer streams. Flame stability is described based on the propagative aspects of the flame leading-edge, by analogy with the temperature dependency of the laminar burning velocity of a stoichiometric mixture. Results show that the jet temperature has a major influence on the lifting of an attached flame, whereas the coflow temperature remains important for the reattachment of a lifted flame. In addition, flame stability experiments have been performed at high levels of both preheating and dilution. Stability maps of critical dilution ratios at lifting have been obtained with preheating. It appears that the ability of a diluent to break flame stability keeps the same relative order as at ambient temperature. It is even enhanced with preheating because higher temperature widens the gap between diluent molar heat capacities $\mathrm{Cp}$. The $\mathrm{Cp}$ approach is however not sufficient to interpret the temperature dependency of the relative influence of the different dilution effects. Furthermore, the role played by the jet flow regime on attached flame stability in dilution-induced lifting experiments is highlighted when dilution is coupled with preheating.

Keywords: Non-premixed combustion; Flame stability; Stability limits; Hysteresis; Preheating; Dilution.

\section{Nomenclature}

Cp molar isobaric heat capacity, $\mathrm{J} /($ mol. $\mathrm{K}$ )

\footnotetext{
${ }^{1}$ Corresponding author. Adress: Centre de Thermique de Lyon (CETHIL) - UMR 5008, Bât. Sadi Carnot, 9 rue de la Physique, INSA-Lyon, Villeurbanne Cedex, F-69621, France. Tel.: +33 (0) 4724384 68; fax : +33 (0) 472438811 .

E-mail adresses: sylvain.lamige@insa-lyon.fr (S. Lamige), jiesheng.min@edf.fr (J. Min), cedric.galizzi@insalyon.fr (C. Galizzi), frederic.andre@insa-lyon.fr (F. André), baillot@coria.fr (F. Baillot), dany.escudie@insaIyon.fr (D. Escudié), lyons@ncsu.edu (K. M. Lyons).
} 
$D_{i} \quad$ injection tube internal diameter, $\mathrm{mm}$

$H \quad$ stabilization height, $\mathrm{mm}$

$K$ diluent coefficient relative to $\mathrm{CO}_{2}$, dimensionless

Q flow rate, $\mathrm{NL} / \mathrm{min}$

$\mathrm{S}_{L, \mathrm{st}}$ stoichiometric laminar burning velocity, $\mathrm{m} / \mathrm{s}$

$T$ measured temperature, $\mathrm{K}$

$T_{s}$ heater set-point temperature, $\mathrm{K}$

$U$ mean flow velocity, $\mathrm{m} / \mathrm{s}$

\section{Greek symbols}

$\alpha \quad$ temperature power exponent (for laminar burning velocity), dimensionless

$\delta \quad$ injection tube lip thickness, $\mathrm{mm}$

\section{Exponents}

- undiluted

\section{Subscripts}

0

at room temperature

a

reattachment (for velocity)

air

relative to the air

$\operatorname{Ar}$

argon

$\mathrm{CO} 2$

carbon dioxide

$\mathrm{CO} 2+\mathrm{Ar} \quad \mathrm{CO}_{2}$ and $\mathrm{Ar}$ mixture having the same molar specific heat capacity as $\mathrm{N}_{2}$

fuel relative to the fuel (methane)

I lifting

N2 nitrogen

ox relative to the oxidizer

ox(diluent) relative to the oxidizer with dilution by (diluent)

ref reference (for temperature)

S relative to laminar burning velocity 


\section{Introduction}

Stabilization mechanisms of non-premixed flames have been investigated for many years. As reviewed by Lyons [1], Chung [2] and Lawn [3], several stabilization theories arose to explain characteristics of lifted flames, the three primary models being based on a) fuel/air premixedness, $b$ ) local flame extinction and c) large eddy or large-scale mixing (see e.g. Kalghatgi [4], Donnerhack and Peters [5] and Miake-Lye and Hammer [6], respectively). Under certain conditions, the same jet exit velocity can lead to two distinct stabilization positions of the flame, either rim-stabilized (often less than $1 \mathrm{~mm}$ from injector tube lip) or lifted several nozzle diameters downstream in the flow. This hysteresis behavior of non-premixed flames between attached and lifted states was first reported by Scholefield and Garside [7]. They interpreted the hysteresis phenomenon from an aerodynamic point-of-view, supported by internal jet transition between laminar and turbulent regimes. From a lifted state, they found that reattachment occurred when the base of the lifted flame reached the top of the laminar part of the jet. A hysteresis phenomenon then occurs because the laminar portion of the jet is reduced for a lifted flame compared to the same exit velocity of an attached flame, as the flame sheet is no longer present to relaminarize the jet flow. In short, the hysteresis zone makes it important whether one approaches stability by turning up, or turning down, the jet flow; different axial positions will be possible for stabilization dependent on the direction in which the region is approached. Stability limits are therefore expressed in terms of lifting and reattachment velocities, as well as blow-out (extinction of a lifted flame) and blow-off (direct extinction of an attached flame with no lifted state) velocities. Later studies have been undertaken on stability limits including for instance effects of coflow $[8,9,10]$ or nozzle size $[9,10]$, which affected mostly the lifted flame and its reattachment but not significantly the attached flame. While of fundamental interest, this issue is important for burner operating/turndown considerations.

Complicating these aforementioned stabilization issues, which have been investigated in room temperature air coflow scenarios, industrial needs for increased efficiency led to practical increases in reactant temperature. Thus, the combustion efficiency is increased, but often along with an increase in the emission of pollutants, such as $\mathrm{NO}_{\mathrm{x}}$. Therefore, with growing interest in cleaner technologies, exhaust gas recirculation has been used instead of direct preheating, either external or internal, eventually giving birth to the flameless combustion regime [11]. The use of such combustion systems involves modifications of stabilization mechanisms, by thermal effects alone, in case of direct air preheating (due to the increase in reactant temperature), or coupled with dilution effects in case of exhaust gas recirculation. In turn, dilution effects combine the impact of pure dilution (reduced oxygen concentration), thermal effects (through the diluent specific heat capacity and thermal diffusivity, and through modification of radiation transfer) and chemical effects (by addition of chemical agents to the chemical chain reaction). It appears therefore crucial to better understand conditions leading to transition between the different combustion regimes for interpreting nonpremixed flame stabilization in light of reactant temperature effects coupled with dilution effects.

The axisymmetric round jet flame configuration is well suited for experiments aimed at understanding flame stabilization physical phenomena. Early experiments on preheating reactants of a non-premixed methane/air flame were performed by Burke and Schuman [12]. By using two preheating temperatures, they experimentally found that preheating reactants had a slight effect on flame height, which they found lower compared to ambient conditions. These authors anticipated two effects due to preheating: an increase in bulk flow velocities, due to a decrease in density at identical reactant inlet flow rates, and an increase in the diffusion coefficient. From their theoretical 
approach, they expected these effects to neutralize themselves in terms of flame height. Their experiments lacked however some accuracy in that the reported preheating temperatures globally represent the furnace temperature, but gave no detailed information on the actual reactant temperatures. In a more detailed work concerning reactant temperature, Takeno and Kotani [13] noted modifications of stability limits with reactant preheating. These authors observed two different steps with increase in jet velocity for hydrogen in air, as well as for city gas in air when sufficient preheating was applied. Above a critical jet velocity, only the laminar part of the flame remained attached to the burner rim, whereas the part above the breakpoint was extinguished. With a further jet velocity increase, the length of that remaining attached part of the flame diminished and eventually extinguished as well. Concurrently, flameless combustion led to research on temperature effects, but mostly turned towards emission of pollutants under high temperature and diluted reactants (see e.g., Wünning and Wünning [14]), where high temperature is defined by Katsuki and Hasegawa [15] as the auto-ignition limit of a given air-fuel mixture. However, as reminded by Oldenhof et al. [16], stabilization mechanisms in flameless combustion remain somewhat different from those in conventional lifted jet flames. Kim et al. [17, 18], experimentally studying a propane jet flame in a preheated air environment, emphasized that the stoichiometric laminar burning velocity $S_{L, s t}$ was a key parameter in flame stabilization and stability. Their results for lift-off height were in agreement with both premixed [4] and large-scale mixing [6] models, provided that temperaturedependent properties were evaluated at initial reactant temperature instead of burned gas temperature as proposed in the original correlations. Overall, preheating has a significant stabilizing effect as previously reported on a non-premixed methane/air flame (see Lamige et al. [19]).

As for dilution, distinct issues are commonly found in the literature concerning either fire safety (e.g., Takahashi [20]) or new combustion technologies based on exhaust gas recirculation (e.g., [21]). It has already been reported that air-side dilution in a coflow jet flame was much more effective than fuel-side dilution in altering flame stability. The relative influence of the three effects occurring with $\mathrm{CO}_{2}$-dilution has been determined by Guo et al. [22]: pure dilution (68\%) appears as having the most important impact on flame stabilization, followed by thermal (22.5\%) and chemical (9.5\%) effects. Radiation and transport effects were found to be negligible in this flame configuration. As concerns soot reactivity [23], these three effects account for $45 \%$ (thermal), $35 \%$ (dilution) and $20 \%$ (chemical) in a $\mathrm{CO}_{2}$-diluted ethylene flame. It has been shown at room temperature $[24,25]$ that when induced by dilution, flame lifting is controlled by the critical flow rate ratio $\left(Q_{\text {diluent }} / Q_{\text {air }}\right)_{\text {lifting. }}$. The use of three different diluents, namely $\mathrm{CO}_{2}, \mathrm{~N}_{2}$ and $\mathrm{Ar}$, allows to classify their ability to break anchored flame stability. Thus, the critical ratio $\left(\mathrm{Q}_{\mathrm{CO} 2} / \mathrm{Q}_{\text {air }}\right)_{\text {lifting }}$ is two and three times lower than $\left(\mathrm{Q}_{\mathrm{N} 2} / \mathrm{Q}_{\text {air }}\right)_{\text {lifting }}$ and $\left(Q_{A r} / Q_{\text {air }}\right)_{\text {lifting, }}$ respectively. This means that $\mathrm{CO}_{2}$ is much more effective to destabilize the flame than the other two diluents, following the molar heat capacity ranking of each diluent.

Even though diluted combustion systems have interested many researchers, the way the dilution effects interact with a higher initial temperature has not been thoroughly investigated, and motivates the present study. In our previous work [22, 24, 25], the influence of air-side dilution on flame stabilization mechanisms and on transitions leading to flame lift-off and extinction was carefully studied at room temperature. Pursuing this initial decoupled approach, results are presented here considering at first only preheating effects for five initial temperatures in addition to experiments at room temperature. Flame stability limits are investigated by careful consideration of the transitions between attached and lifted combustion regimes, expressed through the lifting velocity and the reattachment velocity. Attention is turned to the governing temperature to be 
considered depending on the combustion regime, either in the coflow or in the fuel jet. The chosen approach looks at the temperature-dependent propagation aspects of the leading-edge flame. Subsequently, results are presented on flame stability in both preheated and diluted conditions as occur in practical combustion systems. This second part supports results obtained with dilution at ambient temperature, and combines them with further interpretation of observations made in the first part with preheating. By analyzing the coupled influence of reactant preheating and dilution on flame stability, the present study addresses current issues of flame stabilization mechanisms, shedding light on the physical phenomena involved in transitions between combustion regimes occurring in such conditions.

\section{Experimental Set-up}

2.1. Apparatus description and experimental conditions

\subsubsection{Description}

The present experiment consists of a non-premixed methane jet flame issuing into a co-flowing preheated and/or diluted air stream, as illustrated in figure 1. The whole set-up is a vertical atmospheric furnace, identical to the one used by Min et al. [24]. Methane is injected through a straight tube made of refractory stainless-steel. The tube has a $6.0 \mathrm{~mm}$ internal diameter $D_{i}$ and a 2.1 $\mathrm{mm}$-width lip thickness $\delta$, and its length-to-diameter ratio exceeds 100 to ensure a fully-developed velocity profile at jet exit. Up to two diluents can be added to the air prior to combustion. In this study, four diluents have been used: carbon dioxide, nitrogen, argon and a mixture of carbon dioxide and argon having the same molar heat capacity as nitrogen. A mixing chamber with four cross jets is utilized so that the resulting oxidizer is well homogenized before being preheated. The oxidizer enters the furnace flowing through a tranquilization chamber equipped with two relaminarization grids and followed by a converging section ensuring a flat-plate velocity profile at jet exit-level. Combustion then takes place in the $1 \mathrm{~m}$-length $\times 0.25 \mathrm{~m} \times 0.25 \mathrm{~m}$ square cross-section combustion chamber, also made of refractory stainless steel. Note that the flame is not exposed to room influences due to wall confinement and that the furnace is large enough to avoid any flame-wall direct interaction. Additionally, there is no large-scale recirculation zone inside the combustion chamber, as confirmed both for laminar and turbulent cases through calculated values of the CrayaCurtet number for this configuration [24]. Optical access for flame diagnostics is implemented along the length of the combustion chamber.

\subsubsection{System controls}

The oxidizer and methane temperatures, respectively $T_{o x}$ and $T_{f u e l}$, are measured by K-type thermocouples with $0.2 \mathrm{~mm}$ wire diameter protruding $1 \mathrm{~cm}$ from ceramics insulation. Temperatures are measured in the furnace cross section that contains the fuel tube exit. $T_{\text {fuel }}$ is measured in the fuel flow at the centre of the tube and $T_{\text {ox }}$ is measured in the oxidizer flow at a distance of $30 \mathrm{~mm}$ from the tube centre. The thermocouples are adequately removed whenever required so the flowfield is not impacted at the time of stability limit determination. BROOKS Mass Flow Meters \& Controllers (MFM\&Cs, 5853s model) are employed to control air and methane mass flow rates, whose associated volumetric flow rates are $Q_{\text {air }}$ and $Q_{\text {fuel }}$, respectively. MFM\&Cs full scales are $1000 \mathrm{NL} / \mathrm{min}$ for air and either $100.0 \mathrm{NL} / \mathrm{min}$ or $10.00 \mathrm{NL} / \mathrm{min}$ for methane depending on the required fuel flow rate, as the precision of such flow meters is $\pm 0.2 \%$ of full scale and $\pm 0.7 \%$ of rate. Diluent addition is 
also controlled by Brooks MFMCs of either $300 \mathrm{NL} / \mathrm{min}$ or $400 \mathrm{NL} / \mathrm{min}$ full scales, with gas correction factors applied whenever required. Oxidizer flow rate $Q_{o x}$ is then the sum of diluents and air flow rates, $Q_{\text {diluent }}$ being the flow rate of a given diluent. All velocities reported in this paper, respectively $U_{o x}$ and $U_{\text {fuel }}$ for oxidizer and methane velocity, are mean flow velocities based on flow rates and accounting for density variation with temperature, respectively $T_{o x}$ and $T_{\text {fuel. }}$. This working hypothesis has been confirmed by Laser Doppler Anemometry measurements (with less than $6 \%$ variation).

\subsubsection{Preheating system}

An $18 \mathrm{~kW}$ Sylvania electric heater made up of FeCrAl wires is inserted on air side prior to its entry into the furnace. The heater exit temperature $T_{s}$ can be set up to $1023 \mathrm{~K}$, but considerable heat losses then occur before the jet exit plane. Insulation materials are therefore used around the lower part of the furnace to limit these losses. The maximum air temperature that can be reached at jet exit-level eventually depends on $T_{s}$ and $Q_{o x}$, which will fix both $T_{o x}$ and $U_{o x}$. However, the lower part of the furnace also acts as a co-flowing heat exchanger between air and methane. This way, the preheated air heats the methane as it flows through the fuel tube, up to the temperature $T_{\text {fuel }}$ at nozzle exit. $T_{\text {fuel }}$ is considered in this study as the initial fuel temperature, and is close to but different from $T_{o x}$. Indeed, increased heat transfers towards the fuel at higher injection velocities are counterbalanced by the increased mass flow rate, resulting in a lower $T_{\text {fuel }}$. Therefore, $T_{\text {fuel }}$ is quite dependent on both the methane flow rate $Q_{f u e l}$ and the couple $\left(T_{s}, Q_{o x}\right)$ but in turn, $Q_{f u e l}$ also has a feedback effect on $T_{o x}$. The whole system thus has three main controlling parameters $\left(T_{s}, Q_{o x}, Q_{f u e l}\right)$ and four main variables of interest $\left(U_{o x}, T_{o x}, U_{f u e l}, T_{f u e l}\right)$. Due to the high metal mass of the whole furnace, the system also presents an important thermal inertia before achieving thermal equilibrium. In addition, every change in methane flow rate $Q_{f u e l}$ modifies heat transfers, convective ones along the injection tube and radiative ones due to changes in radiation from the flame. To account for thermal inertia, more delay is then required for each $Q_{\text {fuel }}$ change, accompanied by eventual $T_{s}$ adaptation in order to maintain the selected $\left(U_{o x}, T_{o x}\right)$ parameters constant. In practice, $T_{o x}$ is difficult to maintain at exactly the same temperature for a set of experiments. For sake of simplicity, we therefore introduce an idealized temperature, $T_{o x, \text { ref, }}$, around which some $T_{\text {ox }}$ variations are recorded. Those variations are reported in Appendix A of Supplementary Data with further details on measurement conditions.

One point to be verified was the absence of fuel decomposition prior to combustion due to strong preheating. To that end, the fuel injection tube has been modeled as a simplified plug flow reactor at several temperatures and fed with pure methane. This preliminary study confirmed that no methane cracking occurred before injection tube exit considering residence times and temperatures involved in the present experimental configuration. Complementary information on the furnace thermal behavior can be found in reference [19].

\subsubsection{Experimental conditions}

Given the above-mentioned thermal behavior, the whole range of operating conditions for the different experiments presented here is as follows: both oxidizer and fuel temperatures vary between room temperature and $850 \mathrm{~K}$; oxidizer velocity $U_{o x}$ varies within $0.05-1.18 \mathrm{~m} / \mathrm{s}$ whereas methane jet velocity $U_{\text {fuel }}$ varies between 1.0 and $84 \mathrm{~m} / \mathrm{s}$, with jet Reynolds number $R e_{\text {fuel }}$ varying between 380 (laminar regime) and 13500 (turbulent regime). 


\subsection{Experimental procedure}

2.2.1. Determination of undiluted stability limits with preheating

Once thermal equilibrium is reached in preheating experiments, a two-step procedure is used for determination of flame stability limits. Starting with an attached flame, lifting $U_{l}$ and reattachment $U_{a}$ velocities are first roughly determined. These limits are then precisely determined by varying methane flow rate by $0.1 \mathrm{NL} / \mathrm{min}$ steps close to transition conditions. The waiting time after each step allows for new thermal equilibrium to be attained. Stability limits have been determined for several couple of parameters $\left(T_{o x, r e f}, U_{o x}\right)$.

\subsubsection{Determination of stability limits induced by dilution in preheated conditions}

In a previous paper [24], it has been shown that the dilution procedure had no significant effects on the measured lifting velocity of the diluted attached flame. This conclusion was drawn by using three different dilution procedures:

- Procedure (I): The air mass flow rate was kept constant (and so the oxygen mass flow rate as well), which increased the oxidizer mass flow rate and velocity.

- Procedure (II): The oxidizer velocity was kept constant, which decreased the oxygen mass flow rate.

- Procedure (III): The oxidizer mass flow rate was kept constant, which led to a decrease of the oxygen mass flow rate.

Comparison of these three procedures showed less than $5 \%$ discrepancy within the results. This is due to the minor modification in local velocity field just behind the burner rim where the flame base described as a leading edge stabilizes [26]. However, this point had to be verified with preheating. Indeed, as a greater amount of diluent is required to lift the flame (see 3.2), a greater oxidizer velocity difference is found between procedures. Here, procedures (I) and (III) have been tested. Results of critical dilution ratio for flame lifting $\left(Q_{\text {diluent }} / Q_{\text {air }}\right)_{\text {lifting }}$ agree with less than $7 \%$ difference. Results from procedure (I) only (keeping $Q_{\text {air }}$ constant) are therefore reported here. It should be noted that all dilution ratios reported here are by volume.

The determination of critical dilution ratio for lifting is performed as follows: for a given set of parameters $\left(Q_{\text {air }}, U_{\text {fuel, }}, T_{\text {ox, ref }}\right), Q_{\text {diluent }}$ is progressively increased on the oxidizer side until reaching the $\left(Q_{\text {diluent }} / Q_{\text {air }}\right)_{\text {lifting }}$ limit at which the flame either lifts or blows off. This process is then repeated for several $U_{\text {fuel }}$ and $T_{\text {ox, ref. }}$.

Complementary experiments were conducted, in some cases, to lift the flame by varying the injection velocity at a fixed dilution ratio. Since the results obtained following both methods turned out to be similar, only data obtained using the first method are discussed in this paper.

\section{Results and discussion}

\subsection{Undiluted stability limits}

\subsubsection{Without preheating}

Lifting and reattachment velocities have been determined following the procedure described in 2.2. Figure 2 presents the critical jet velocities between the attached and lifted regimes for various 
oxidizer velocities with reactants initially at room temperature, where lifting velocity $U_{l}$ is displayed with filled stars and reattachment velocity $U_{a}$ with empty stars. The corresponding lift-off height at lifting is about $6 D_{i}$ in a $0.2 \mathrm{~m} / \mathrm{s}$ air coflow. Note that jet Reynolds number indicated on the right ordinate show a flame reattachment in the mid-2000s, consistent with the classic observations of the reattachment from a turbulent lifted flame to a laminar attached flame $[27,28]$. These results are consistent with those obtained in the same configuration by Min et al. [24]. It can be noted that the air velocity effect is insignificant in the range considered, as lifting velocity remains almost constant at about $16.5 \mathrm{~m} / \mathrm{s}$ whereas reattachment velocity is approximately equal to $7.0 \mathrm{~m} / \mathrm{s}$. The observed independence of the lifting velocity from the coflow velocity applies because of the relatively thick burner rim employed in this study: it acts as a protection for the flame leading edge against the upcoming coflow velocity. Indeed, this corresponds to a particular type of lifting, as mentioned in our previous study [25] or in [10] and [29], and as illustrated for example by Takahashi and Schmoll [30] with their $2.4 \mathrm{~mm}$-thick burner rim experiments.

\subsubsection{Influence of reactant initial temperature}

Increasing reactant initial temperature leads to several changes in reactive and thermophysical properties. The chosen approach here being based on the propagative aspects of the flame and their links to the stabilization mechanisms and the stability limits, a particular focus is made on the temperature dependency of the stoichiometric laminar burning velocity. Indeed, $S_{L, s t}$ follows a temperature power law: $S_{L, s t} \propto S_{L, s t, 0} \times\left(T / T_{0}\right)^{\alpha}$, where $S_{L, s t, 0}$ is the value of $S_{L, s t}$ at ambient temperature $T_{0}$ [31]. Values of the power exponent, $\alpha_{S}$, for methane/air flames reported in the literature for unity equivalence ratio and at fixed pressure close to $1 \mathrm{~atm}$ are quite scattered, and range between 1.4 and 2.6 [32]. The value of $\alpha_{S}=1.575$ proposed by Mishra for a stoichiometric methane-air mixture between $300 \mathrm{~K}$ and $600 \mathrm{~K}$ [31] has been used for calculations in this paper. It was already shown that $S_{L, s t}$ played a predominant role in flame stabilization, in preheating conditions [18] as well as in dilution experiments $[24,25]$.

Figure $3 a$ then gives the evolution of $U_{l}$ and $U_{a}$ at oxidizer initial temperatures $T_{\text {ox, ref }}$ of $370 \mathrm{~K}, 450$ $\mathrm{K}, 520 \mathrm{~K}, 625 \mathrm{~K}$ and $800 \mathrm{~K}$. Results at ambient temperature from figure 2 are also reported for comparison purposes. The corresponding stabilization heights at lifting vary with preheating between $6 D_{i}$ down to $4 D_{i}$ (in a $0.2 \mathrm{~m} / \mathrm{s}$ air coflow except for the $800 \mathrm{~K} T_{\text {ox, ref }}$ case for which the coflow velocity is $0.5 \mathrm{~m} / \mathrm{s}$ ). Figure $3 \mathrm{~b}$ presents the corresponding jet Reynolds number: values remain in the range 5000-6000 at lifting and 2200-3200 at reattachment, which is still coherent with the transitional Reynolds number at reattachment as previously discussed. Coflow velocity effects are still negligible, for the same reasons as invoked at ambient temperature. However, preheating effects are obvious in figure $3 a$, where both lifting and reattachment velocities are shown to be higher with an increase in preheating. Another noticeable feature on transition velocities presented in figure $3 a$ is the greater

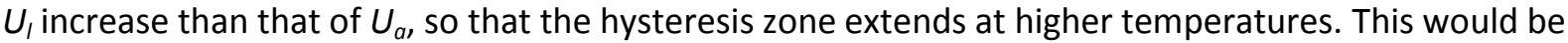
more easily recognized by plotting $U_{l}$ and $U_{a}$ directly against reactant initial temperature. This first issue centers on determining what temperature should be considered for such plotting, the jet or the coflow temperature. Both have been tested, along with fitting using a temperature power law in similarity with the temperature dependency of $S_{L, s t}$. Table 1 presents curve fit results, globally found satisfactory for both stability limits and both reference temperature tested. It appears however that the power exponent value better corresponding to $S_{L, s t}$ one $\left(\alpha_{S}=1.575\right)$ differs depending on the considered transition: for the reattachment velocity, $\alpha_{a}$ is closer to $\alpha_{S}$ when air initial temperature is 
taken as reference $\left(\alpha_{a, o x}=1.561\right)$, whereas for flame lifting $\alpha_{l}$ better matches $\alpha_{s}$ when fuel initial temperature is taken as reference $\left(\alpha_{l, f u e l}=1.641\right)$. Those results are summarized in figure 4 in which fuel velocities corresponding to stability limits are plotted against $T_{o x}$ for the reattachment transition but against $T_{\text {fuel }}$ for the lifting transition.

Table 1 Curve fit results for the temperature exponent of lifting and reattachment velocities as a temperature power law

\begin{tabular}{|c|c|c|c|c|}
\hline \multirow{2}{*}{$\begin{array}{l}\text { Considered } \\
\text { transition }\end{array}$} & \multicolumn{2}{|c|}{$T_{o x}$ as reference temperature } & \multicolumn{2}{|c|}{$T_{\text {fuel }}$ as reference temperature } \\
\hline & $\begin{array}{c}\text { Temperature } \\
\text { exponent } \alpha\end{array}$ & $\mathbf{R}^{2}$ & $\begin{array}{c}\text { Temperature } \\
\text { exponent } \alpha\end{array}$ & $\mathbf{R}^{2}$ \\
\hline Reattachment & $\alpha_{a, o x}=1.561$ & 0.969 & $\alpha_{a, f u e l}=1.809$ & 0.964 \\
\hline Lifting & $\alpha_{1, o x}=1.247$ & 0.969 & $\alpha_{l, f u e l}=1.641$ & 0.992 \\
\hline
\end{tabular}

According to Kim et al. [18], ratios of critical velocities made dimensionless by $S_{L, s t}$ keep near constant values regardless of the initial reactant temperature. In the particular configuration used by Kim et al. (1.65 mm nozzle diameter, $0.765 \mathrm{~mm}$ lip thickness), these ratios took the values $U_{I} / S_{L, s t} \approx C_{\text {I }}$ $=23$ and $U_{a} / S_{L, s t} \approx C_{a}=17$, thus with $C_{l}>C_{a}$. For comparison purposes, results from figure 4 have been plotted in figure 5 with critical velocities made dimensionless by $S_{L, s t}$. Based on what has been discussed concerning the reference temperature to choose depending on the considered transition, $S_{L, s t}$ is calculated with $T_{o x}$ as reference for flame reattachment, whereas it is calculated with $T_{\text {fuel }}$ as reference for flame lifting. This way, the ratio $U_{a} / S_{L, s t}$ keep a constant value close to $C_{a}=18$, and close to $C_{l}=44$ for the $U_{l} / S_{L, s t}$ ratio. It can be noted that the $C_{l}$ value is not far from the one found by Kim et al. [18]; this may indicate that when the flame is not under the direct influence of the burner, as is the case for the reattachment process, the transition between lifted and attached flame states occurs for a jet velocity mostly imposed by the corresponding $S_{L, s t}$. Nonetheless, this would require confirmation by comparison with other data obtained in different configurations. On the contrary, the $U_{I} / S_{L, s t}$ ratio found in this study $\left(C_{l}=44\right)$ is much greater than the value found by Kim et al. $\left(C_{l}=\right.$ 23) [18]. The difference in fuel between the experiments of Kim et al. (propane) and the present work (methane) is taken into account through $S_{L, s t}$ values. That means that transition ratios are dependent on other factors such as geometrical conditions, and in particular, on lip thickness for the lifting process of attached flames (see e.g. Otakeyama et al. [29] or Takahashi and Schmoll [30] for detailed effects of the lip thickness). In addition, figure 5 specifies bulk oxidizer velocities $U_{o x}$ confirming once again that this is not a preponderant parameter in the studied $U_{o x}$ range.

What should be retained from the above results is that the jet has less thermal impact at the lifted flame base than the coflow. Evidence is also given that the jet temperature has much more importance in the lifting process than in the reattachment process, in which oxidizer conditions gains importance. This had not been observed in previous similar experiments, since fuel and oxidizer were always at the same initial temperature. Here, conversely, the difference between fuel and oxidizer temperatures provides information on the relative thermal influence of both streams. On the one hand, the reattachment of a lifted jet flame is thermally influenced mostly by its environment, that is, the coflow. This is consistent with the proportions of each reactant encountered at the flame base where it stabilizes: more air comes from the coflow stream than fuel from the jet stream. On the other hand, the close influence of the burner makes things work differently for the lifting of an anchored flame. The thick burner lip is likely to have important thermal effects on the stabilization mechanisms of the attached flame. In addition, the wake behind the burner rim helps the attached 
flame to stabilize against higher jet velocities. This goes along with a global displacement of the flame toward the methane jet [24], which is consistent with a greater influence of the jet temperature. Consequently, the relevant governing temperature clearly depends on which combustion regime transitions are considered. Here, those are interpreted through the propagation aspects of the flame edge dynamics, both from attached and lifted flame states, provided that the relevant stream temperature is considered, respectively $T_{\text {fuel }}$ or $T_{\text {ox }}$. This interpretation indicates that stoichiometric conditions are representative of the temperature dependency of the laminar burning velocity involved in the stabilization mechanism, even for an attached flame. Indeed laminar burning velocities further from stoichiometry (both on the rich and lean sides) present a similar dependency to temperature but with a slightly higher temperature exponent, as detailed for example in Konnov's work [32].

\subsection{Dilution-induced lifting in the presence of preheating}

Critical dilution ratios at lifting (or blow-off), defined as $\left(\mathrm{Q}_{\text {diluent }} / \mathrm{Q}_{\text {air }}\right)_{\text {lifting, }}$, have been previously determined at ambient temperature for a set of different diluents (Min et al. [24, 25]), following the procedures presented in 2.2.2. Here, flame lifting experiments are performed with the same diluents $\left(\mathrm{CO}_{2}, \mathrm{~N}_{2}\right.$ or $\left.\mathrm{Ar}\right)$ and the same experimental procedure for three preheating temperatures, namely 450 $\mathrm{K}, 600 \mathrm{~K}$ and $850 \mathrm{~K} T_{\text {ox,ref. }}$ The associated undiluted air mean flow velocities are $0.17 \mathrm{~m} / \mathrm{s}, 0.17 \mathrm{~m} / \mathrm{s}$ and $0.76 \mathrm{~m} / \mathrm{s}$ respectively. This great velocity value is due to the higher oxidizer flow rate which is required to obtain such a high initial oxidizer temperature, $850 \mathrm{~K}$. Results obtained with $\mathrm{CO}_{2}$ as diluent are firstly presented in figure 6 , including the ambient temperature case.

It has already been shown that a high oxidizer temperature enhances the attached flame stability (cf. 3.1.2), and air-side dilution by $\mathrm{CO}_{2}$ has the ability to break flame stability [24, 25]. Here, preheating and dilution compete in promoting or weakening flame stability. A similar evolution of all curves in figure 6 is observed regardless of the preheating temperature. For a given dilution ratio $Q_{\mathrm{CO} 2} / Q_{\text {air }}$, an attached flame can sustain higher jet velocities $U_{\text {fuel }}$ with increased $T_{\text {ox,ref, }}$, whereas for a constant $T_{\text {ox, ref, }}$ an increase in the dilution ratio $Q_{\mathrm{CO} 2} / Q_{a i r}$ lessens the maximum jet velocity $U_{\text {fuel }}$ the flame can withstand. The stable attached flame domain is therefore extended in this (dilution ratio, jet velocity) mapping, since an attached flame can be held for higher jet velocities and dilution ratios in preheated conditions than at ambient temperature. This competition between jet aerodynamics and dilution, already discussed in $[24,25]$ at ambient temperature, is confirmed here in preheating conditions. Hereafter, explanations based on the physical phenomena involved eventually bring to normalizations of abscissa and ordinate leading to a consistent evolution of all results from figure 6.

\subsubsection{Effects of preheating on $\mathrm{CO}_{2}$-dilution induced lifting}

Another feature can be noticed in figure 6 both with and without dilution: each curve undergoes a change of slope. In our previous work at ambient temperature [24, 25], this change of slope was directly related to the modification of the methane flow regime from laminar to turbulent, which could be quantified through the jet Reynolds number $R e_{\text {fuel }}=U_{\text {fuel }} \rho_{\text {fuel }} D_{i} / \mu_{\text {fuel. }}$ In order to check the consistency of this finding at higher reactant temperature, the original abscissa, methane velocity $\left(U_{\text {fuel }}\right)$, is proposed to be replaced by its Reynolds number $R e_{\text {fuel, }}$, as shown in Figure 7 a. After this abscissa normalization, the point of inflection of these curves collapse on a same Reynolds number around 2000, a usual value for the beginning of the transition from laminar to turbulent regime in a pipe flow. This confirms that the change of slope is due to the modification of the methane jet flow 
regime from laminar to turbulent, regardless of the preheating temperature. In addition, the points corresponding to the flame lifting achieved by methane velocity only without dilution are found to locate almost at a same value of Reynolds number as well, as already noted in Figure $3 \mathrm{~b}$. This supposes that flame lifting occurs once a critical value of Reynolds number characterizing methanejet dynamics is attained. Hence, the key parameter here is the Reynolds number, taking into account the temperature effect through density $\left(\rho_{\text {fuel }}\right)$ and viscosity $\left(\mu_{\text {fuel }}\right)$ terms. These two parameters vary in function of temperature through the following relationships:

$\rho_{\text {fuel }} \propto T^{1}$, according to perfect gas equation

$\mu_{f u e l} \propto T^{2 / 3}$, as implied by correlations for calculating gas viscosity [33]

Therefore, the ratio $\mu_{\text {fuel }} / \rho_{\text {fuel }}$ has a temperature-depending law, expressed as $\mu_{\text {fuel }} / \rho_{\text {fuel }} \propto T^{5 / 3}$. In this way, it is also possible to replace the methane jet Reynolds number by the following expression where the temperature effect is explicitly integrated, $U_{\text {fuel }} /\left(T_{\text {fuel }} / T_{0}\right)^{5 / 3}$, with the subscript 0 indicating room temperature. This has been done in figure $7 \mathrm{~b}$, which supports this analysis.

As concerns the ordinate "dilatation" observed between curves obtained for $\mathrm{CO}_{2}$-dilution at different preheating temperatures, once again the initial temperature may be invoked to explain this phenomenon. Here dilution ratios are directly affected by increase in $S_{L, s t}$ with temperature, as can be observed in figure 8 . Indeed, the ratio $\left(T_{\text {fuel }} / T_{0}\right)^{1.575}$ in figure 8 corresponds to the ratio $\left(S_{L, s t} / S_{L, s t, o}\right)$. In short, $\mathrm{CO}_{2}$-dilution ratios at lifting are controlled by jet dynamics as well as premixed flame properties, which are both temperature dependent, explaining the observed shift with preheating. The flame burning velocity $S_{L, s t}$ is thus confirmed to be here a key parameter characterizing the flame leading edge dynamics, supporting findings obtained in undiluted preheating conditions (cf. 3.1.2) as well as with dilution at room temperature [25].

\subsubsection{Comparison between diluents}

Figure 9 then presents results at $295 \mathrm{~K}, 450 \mathrm{~K}$ and $600 \mathrm{~K}$ for the four tested diluents: $\mathrm{CO}_{2}, \mathrm{~N} 2 \mathrm{Ar}$ and a $\left(\mathrm{CO}_{2}+\mathrm{Ar}\right)$ mixture with $\mathrm{Cp}$ equivalent to that of $\mathrm{N}_{2}$. A similar evolution of the critical dilution ratio with an increase in reactant initial temperature is observed for all diluents tested here. It appears that the diluent ranking found at room temperature $[20,24]$ is conserved here with preheating: $\mathrm{CO}_{2}$ has the greatest ability to break flame stability, followed by $\mathrm{N}_{2}$ and Ar. As noted by Takahashi et al. [20], this order follows the molar heat capacity ranking of these diluents, thus attributing the major effect of diluent addition to the diluent's thermal properties. However, the $\left(\mathrm{CO}_{2}+\mathrm{Ar}\right)$ mixture, first introduced in Min et al.'s work [24] and also used here with preheating, makes it clear that the diluent molar $\mathrm{Cp}$ is not the sole controlling parameter. Min et al. therefore defined a new parameter, $K_{\text {diluent }}=\left(Q_{\text {diluent }} / Q_{\text {air }}\right)_{\text {lifting }} /\left(Q_{\mathrm{co} 2} / Q_{\text {air }}\right)_{\text {lifting }}[24,25]$, quantifying the capacity of a diluent to act on the flame destabilization process, relative to $\mathrm{CO}_{2}$. Thus, $K_{\text {diluent }}$ not only encompasses thermal effects due to diluent molar specific heat capacity, but also all other effects such as pure dilution or chemical effects, whatever their relative impact [22]. $K_{\text {diluent }}$ characterizes the flame lifting under the action of a diluent compared to that of $\mathrm{CO}_{2}$. Values determined at room temperature were: $\left(K_{\mathrm{CO} 2}=1\right)<\left(K_{\mathrm{CO} 2+\mathrm{Ar}}=1.6\right)<\left(K_{\mathrm{N} 2}=1.9\right)<\left(K_{\mathrm{Ar}}=2.9\right)[24,25]$. Following the same methodology as at room temperature, these values have been employed in figure 10 for plotting again results using the parameter $\left(Q_{\text {diluent }} / Q_{\text {air }}\right.$ lifting $/ K_{\text {diluent }}$ in ordinate. This way, results for all diluents in figure 10 follow the same evolution with temperature as observed for $\mathrm{CO}_{2}$ in figure 6 . 
The coupled effects of dilution and preheating can therefore be explained in the same way as previously performed for $\mathrm{CO}_{2}$ dilution (3.2.1). Temperature effects appear twice in this critical dilution ratio mapping: through modification of the jet flow regime, as well as through modification of the flame propagation properties. Coupling of preheating with dilution is thus interpreted as a cursor displacement in the jet aerodynamics-dilution competition. Consequently, the analysis that led to the establishment of figure 8 can be similarly employed with results of figure 10 for all diluents once $K_{\text {diluent }}$ has been taken into account, as shown in figure 11.

However, it can be noted that though data properly collapse on a single curve at room temperature, the agreement is not that good at higher $T_{o x, \text { ref. }}$. This raises the issue of the temperature dependence of $K_{\text {diluent }}$. In order to investigate this, effective $K_{\text {diluent }}$ values have been calculated for each $T_{\text {ox, ref }}$ as $\left(Q_{\text {diluent }} / Q_{\text {air }}\right)_{\text {lifting }} /\left(Q_{c o 2} / Q_{\text {air }}\right)_{\text {lifting }}$ values averaged over the whole $U_{\text {fuel }}$ range, and plotted in figure 13. $K_{\text {diluent }}$ is found to increase with temperature, with more significant changes occurring for $K_{A r}$ as shown by the values obtained at $600 \mathrm{~K} T_{\text {ox,ref }}:\left(K_{C O 2}=1\right)<\left(K_{N 2}=2.1\right)<\left(K_{A r}=3.7\right)$. In figure 13, diluent molar heat capacities have also been added for comparison purposes as an analysis tool.

It is noteworthy that when $C p_{\mathrm{CO} 2}$ increases by $27 \%$ from $37.3 \mathrm{~J} /(\mathrm{mol} . \mathrm{K})$ to $47.4 \mathrm{~J} /(\mathrm{mol} . \mathrm{K})$ between $295 \mathrm{~K}$ and $600 \mathrm{~K} T_{o x, r e f}$, the corresponding increase is only $3 \%$ for $C p_{N 2}$, from $29.2 \mathrm{~J} /(\mathrm{mol} . \mathrm{K})$ to 30.1 $\mathrm{J} /\left(\right.$ mol.K), whereas for the same temperature range, preheating has no effect on $C p_{A r}$ which remains nearly constant at $20.8 \mathrm{~J} /(\mathrm{mol} . \mathrm{K})$. Consequently, the molar heat capacity of the oxidizer near lifting will greatly be affected by this thermo-physical change, above all at low jet velocities when the lifting dilution ratio is higher. For instance at $600 \mathrm{~K} T_{o x, \text { ref, }}$, near dilution lifting for $U_{\text {fuel }} / U_{l}^{\circ}=0.07$ (where $U_{l}^{\circ}$ represents the undiluted lifting velocity), the $\mathrm{CO}_{2}$-diluted oxidizer molar heat capacity $C p_{\text {ox }(\mathrm{CO} 2)}$ is 33.9 $\mathrm{J} /\left(\right.$ mol.K) compared to the $25.9 \mathrm{~J} /\left(\right.$ mol.K) for $C p_{o x(A r)}$. This difference is much higher than at ambient temperature for the same $U_{\text {fuel }} / U_{l}^{\circ}$ ratio near dilution lifting, where $C p_{\text {ox }(C O 2)}$ is $29.9 \mathrm{~J} /(\mathrm{mol} . \mathrm{K})$ and $C p_{\text {ox }(A r)}$ is $27.3 \mathrm{~J} /(\mathrm{mol} . \mathrm{K})$, hence the increase in $K_{A r}$ with preheating. In other words, the higher the initial temperature, the higher the dilution ratio required to lift the flame and the greater the difference in oxidizer molar heat capacity according to the diluent nature. This study confirms that the temperature-dependency of diluent molar heat capacities does play an important role in the observed evolution of $K_{\text {diluent }}$ with temperature. Nevertheless, the explanation presented above does not hold satisfactorily for all diluents tested here. For instance, although $\mathrm{N}_{2}$ and the $\left(\mathrm{CO}_{2}+\mathrm{Ar}\right)$ mixture have the very same $\mathrm{Cp}$, a different evolution of their respective $K_{\text {diluent }}$ is observed with temperature. Other factors should therefore be taken into account for a full understanding of $K_{\text {diluent }}$ thermal sensitivity, such as chemical effects, which are affected by these temperature changes since chemical reaction paths are highly temperature-dependent.

It appears that further work is required, first concerning flame propagation aspects, to investigate the existing links between the laminar burning velocity $S_{L, s t}, \mathrm{Cp}$ and dilution when coupled with preheating, as initiated in some way by Galmiche et al. [34]. In addition, a second aspect should be looked at in further work, concerning the different phenomena involved with dilution. Those are essentially pure dilution, thermal and chemical effects, but other effects such as radiation ones may not be negligible at higher reactant temperature. It would be necessary to further analyze how their relative influence is affected when preheating comes on top of dilution. Indeed, they may not keep the same relative importance at higher temperature, and that could help interpreting the way the parameter $K_{\text {diluent }}$ evolve with temperature. 


\section{Conclusions}

Effects of preheating on stabilization and stability limits of a non-premixed methane jet flame have been studied for six initial reactant temperatures up to $850 \mathrm{~K}$, for a coflow of either pure or diluted air. Both transitions between attached and lifted flame states have been studied. It has been shown that flame stability is substantially increased with preheating, since an attached flame is able to sustain much higher jet velocities with higher initial reactant temperatures. This increase in both lifting and reattachment velocities was found to correlate particularly well with values of the temperature-dependent stoichiometric laminar burning velocity $S_{L, s t}$, a governing property of the premixed-like edge-flame behavior. The difference between fuel and oxidizer temperatures, nonexistent in previous similar experiments, gives information on the relative thermal influence of both streams. The jet temperature has much more importance in the lifting process of the attached flame, whereas the oxidizer conditions remain important in the lifted flame reattachment process. Ratios of transition velocities made dimensionless by $S_{L, s t}$ maintain near constant values whatever the initial reactant temperature, provided that the jet temperature and oxidizer temperature are respectively taken as reference values for determination of the lifting and reattachment ratios. Future research work should take care to select a pertinent temperature reference, since the jet, coflow or even the burner rim temperature will not impact flame stability in the same manner.

The predominant role of $S_{L, s t}$ highlighted here with preheating is also confirmed when preheating is coupled with dilution, where both phenomena compete in promoting and weakening flame stability. Dilution-induced stability limits have been obtained at several preheating temperatures up to $850 \mathrm{~K}$ and for a set of four diluents: $\mathrm{CO}_{2}, \mathrm{~N}_{2}$, $\mathrm{Ar}$ and a $\left(\mathrm{CO}_{2}+\mathrm{Ar}\right)$ mixture having a molar heat capacity equivalent to that of $\mathrm{N}_{2}$. Compared to critical dilution ratios obtained at ambient temperature, preheating affects results in two ways. Firstly, the change of slope observed in dilution stability maps is linked to the flow regime of the jet, either laminar or turbulent. This had been noticed at room temperature and is confirmed here with preheating since the initial reactant temperature directly affects this flow regime through modifications of the Reynolds number, proportional to the temperature ratio (initial temperature to ambient temperature) brought to the power $5 / 3$. Secondly, the rise in $S_{L, s t}$ with temperature also impacts the dilution limit. Indeed, $S_{L, s t}$ is decreased with dilution, whereas preheating counterbalances it by increasing $S_{L, s t}$. Consequently, dilution limits are directly modified with preheating by the relative change in $S_{L, s t}$. However, further studies would be required on $S_{L, s t}$ determination to extend its validity range in order to include the extreme conditions of initial temperature and dilution ratios encountered in practical applications.

In addition, diluents keep the same relative flame destabilizing order as at room temperature. This can be globally quantified through the parameter $K_{\text {diluent }}$, with $K_{\mathrm{CO} 2}<K_{\mathrm{N} 2}<K_{\mathrm{Ar}}$. However, $K_{\text {diluent }}$ values increase with preheating, above all as concerns argon. This latter evolution can be linked to the relative temperature-dependency of $\mathrm{CO}_{2}$ and $\mathrm{Ar}$ molar heat capacities, their difference being widened with preheating. However, comparison with other diluents such as $\mathrm{N}_{2}$ and $\left(\mathrm{CO}_{2}+\mathrm{Ar}\right)$ reveals that other factors, distinct from thermal effects due to molar heat capacity, should also be taken into account. More work would still be required to analyze how temperature affects the relative influence of the different dilution effects when coupled with preheating. 


\section{Acknowledgment}

This work was supported by the French National Research Agency (ANR-06-BLAN-0255). Authors also acknowledge the help provided by Pierre-Alexandre Glaude (Reactions and Chemical Engineering Laboratory, UPR CNRS 3349, Nancy, France) on the issue of high-temperature methane cracking in the injection tube. One of the authors (KML) would like to acknowledge partial support from the U.S. Army Research Office (Grant W911-NF-12-1-0140), as well as from INSA-Lyon (Université de Lyon, F-69621, Villeurbanne, France). 


\section{References}

[1] K.M. Lyons, Prog. Energy Combust. Sci. 33 (2007) 211-231.

[2] S.H. Chung, Proc. Combust. Inst. 31 (2007) 877-892.

[3] C.J. Lawn, Prog. Energy Combust. Sci. 35 (2009) 1-30.

[4] G.T. Kalghatgi, Combust. Sci. Technol. 41 (1984) 17-29.

[5] S. Donnerhack, N. Peters, Combust. Sci. Technol. 41 (1984) 101-108.

[6] R.C. Miake-Lye, J.A. Hammer, Proc. Combust. Inst. 22 (1989) 817-824.

[7] D. Scholefield, J. Garside, Symp. Combust. Flame Explos. Phenom. 3 (1949) 102-110.

[8] A. Wyzgolik, F. Baillot, Proc. Combust. Inst. 31 (2007) 1583-1590.

[9] S.D. Terry, K.M. Lyons, Combust. Sci. Technol. 177 (2005) 2091-2112.

[10] T. Leung, I. Wierzba, Proc. Combust. Inst. 32 (2009) 1671-1678.

[11] A. Cavaliere, Prog. Energy Combust. Sci. 30 (2004) 329-366.

[12] Burke and Schumann, Proc. Symp. Combust. 1 (1928) 2-11.

[13] T. Takeno, Y. Kotani, Acta Astronaut. 2 (1975) 999-1008.

[14] J.A. Wünning, J.G. Wünning, Prog. Energy Combust. Sci. 23 (1997) 81-94.

[15] M. Katsuki, T. Hasegawa Proc. Combust. Inst. 27 (1998) 3135-3146.

[16] E. Oldenhof, M.J. Tummers, E.H. van Veen, D.J.E.M. Roekaerts, Combust. Flame 157 (2010) 16671178.

[17] K. Kim, S. Won, S. Chung, Proc. Combust. Inst. 31 (2007) 947-954.

[18] K. Kim, S. Won, S. Chung, Proc. Combust. Inst. 31 (2007) 1591-1598.

[19] S. Lamige, C. Galizzi, J. Min, J. Perles, F. André, F. Baillot, D. Escudié, 14th Int. Heat Transf. Conf., ASME, Washington, U.S., 2010.

[20] F. Takahashi, G.T. Linteris, V.R. Katta, Proc. Combust. Inst. 31 (2007) 2721-2729.

[21] B.B. Dally, E. Riesmeier, N. Peters, Combust. Flame 134 (2004) 418-431.

[22] H. Guo, J. Min, C. Galizzi, D. Escudié, F. Baillot, Combust. Sci. Technol. 182 (2010) 1549-1563.

[23] K. Al-Qurashi, A.D. Lueking, A.L. Boehman, Combust. Flame 158 (2011) 1696-1704.

[24] J. Min, F. Baillot, A. Wyzgolik, E. Domingues, M. Talbaut, B. Patte-Rouland, C. Galizzi, Combust.

Sci. Technol. 182 (2010) 1782-1804.

[25] J. Min, F. Baillot, Combust. Flame 159 (2012) 3502-3517.

[26] F. Takahashi, V.R. Katta, Proc. Combust. Inst. 28 (2000) 2071-2078.

[27] D. Scholefield, J. Garside, Symp. Combust. Flame Explos. Phenom. 3 (1949) 102-110.

[28] S. Gollahalli, Ö. Savas, R. Huang, J.R. Azara, Proc. Combust. Inst. 21 (1988) 1463-1471.

[29] Y. Otakeyama, T. Yokomori, M. Mizomoto, Proc. Combust. Inst. 32 (2009) 1091-1097.

[30] F. Takahashi, W.J. Schmoll, Proc. Combust. Inst. 23 (1991) 677-683.

[31] D.P. Mishra, Fuel 82 (2003) 1471-1475.

[32] A.A. Konnov, Fuel 89 (2010) 2211-2216.

[32] Y. Otakeyama, T. Yokomori, M. Mizomoto, Proc. Combust. Inst. 32 (2009) 1091-1097.

[33] K.K. Kuo, Principles of Combustion, second ed., Wiley, Hoboken, U.S., 2005.

[34] B. Galmiche, F. Halter, F. Foucher, P. Dagaut, Energy Fuel 25 (2011) 948-954. 


\section{Figure captions}

Figure 1 Diagram of experimental set-up.

Figure 2 Lifting and reattachment velocities at room temperature with corresponding critical Reynolds number in secondary ordinate.

Figure 3 (a) Lifting and reattachment velocities with preheating and (b) corresponding critical Reynolds number.

Figure 4 Power law fitting of undiluted stability limits with air temperature taken as reference for reattachment and fuel temperature taken as reference for lifting.

Figure 5 Critical velocities made dimensionless by $S_{L, s t}$ with oxidizer temperature taken as reference for reattachment and fuel temperature taken as reference for lifting.

Figure $6 \mathrm{CO}_{2}$-dilution ratios at lifting vs. jet velocity for several preheating temperatures.

Figure 7 Results from figure 6 with modified abscissa by (a) using the jet Reynolds number instead of jet velocity or (b) dividing jet velocity by the term $\left(T_{\text {fuel }} / T_{0}\right)^{5 / 3}$.

Figure 8 Results from figure $7 \mathrm{~b}$ with critical dilution ratios divided by $\left(T_{\text {fuel }} / T_{0}\right)^{1.575}$.

Figure 9 Critical dilution ratios at lifting vs. jet velocity for $\mathrm{CO}_{2}, \mathrm{~N}_{2}$, $\mathrm{Ar}$ and $\mathrm{CO}_{2}+\mathrm{Ar}$ at three initial temperatures.

Figure 10 Results from figure 9 taking into account the parameter $K_{\text {diluent }}$.

Figure 11 Results from figure 10 with temperature effects explicitly integrated by dividing by $\left(T_{\text {fuel }} / T_{0}\right)^{5 / 3}$ in abscissa and by $\left(T_{\text {fuel }} / T_{0}\right)^{1.575}$ in ordinate.

Figure 12 Temperature dependency of diluent molar heat capacities and $K_{\text {diluent }}$. 
Figurjedtion tube cross section

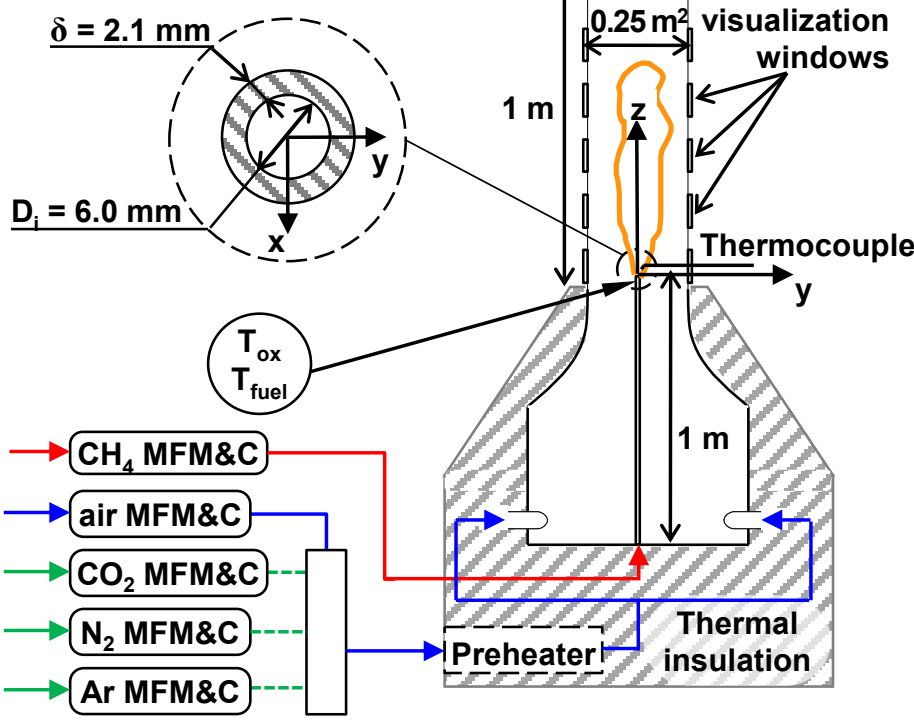




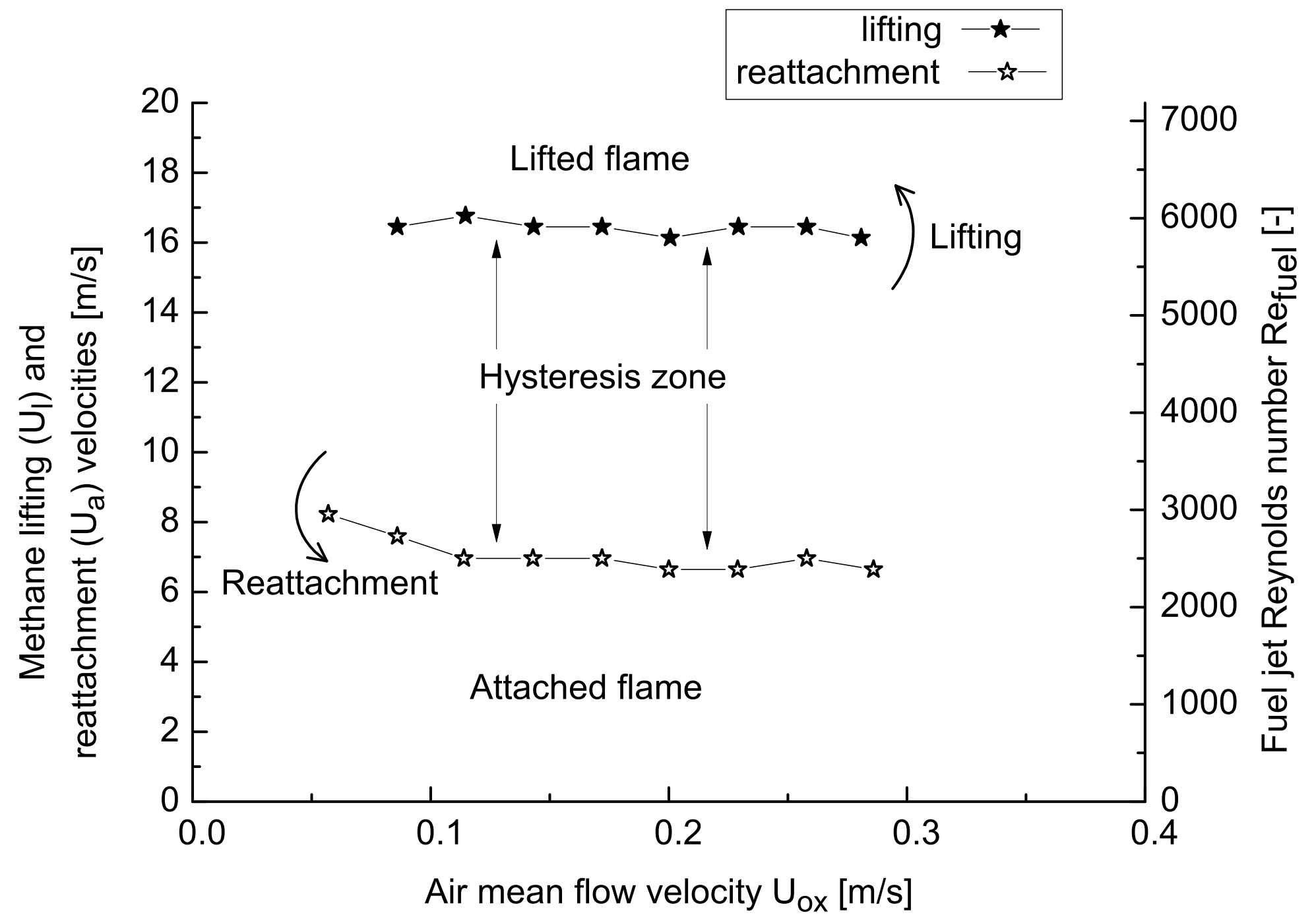




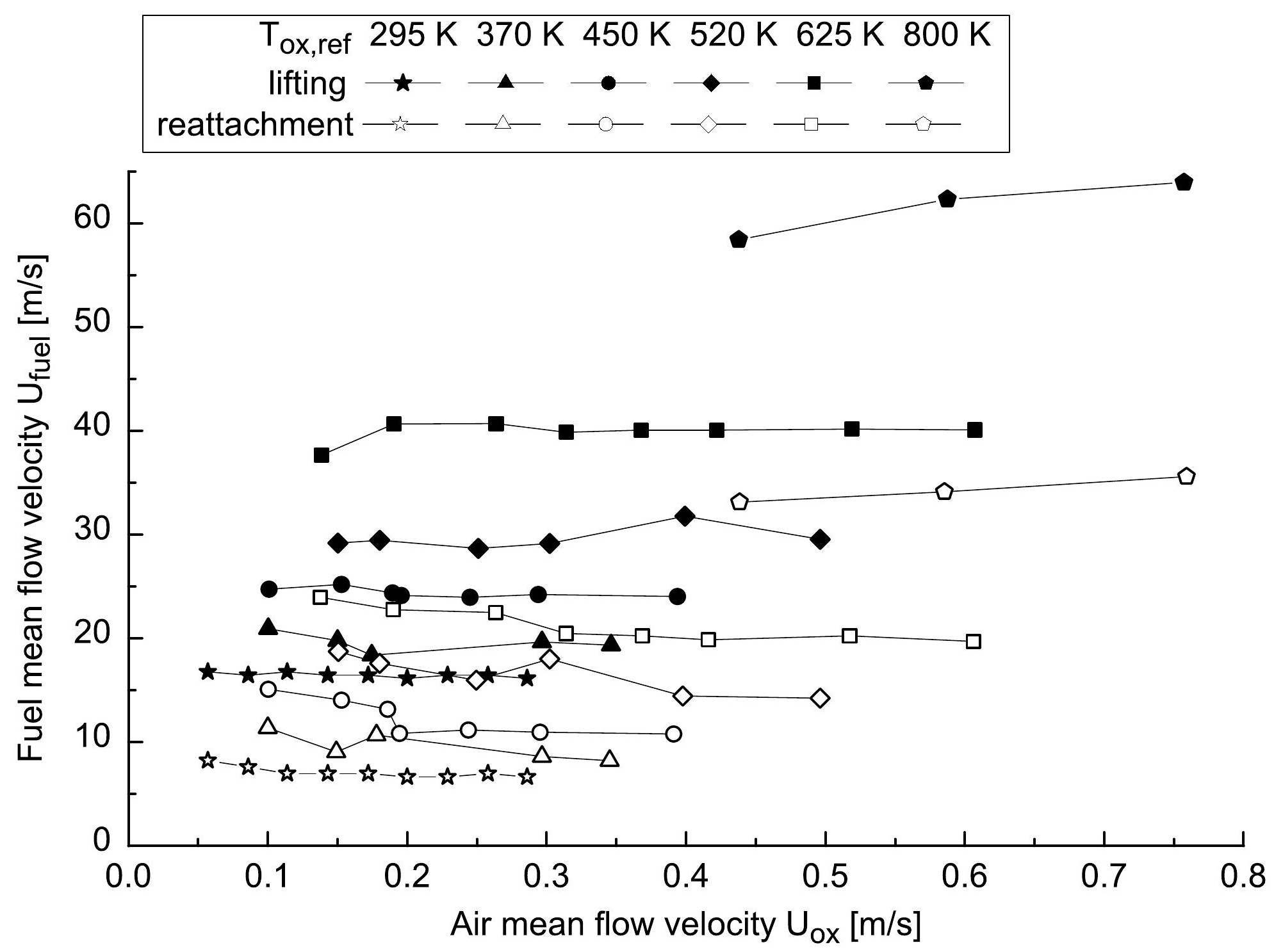




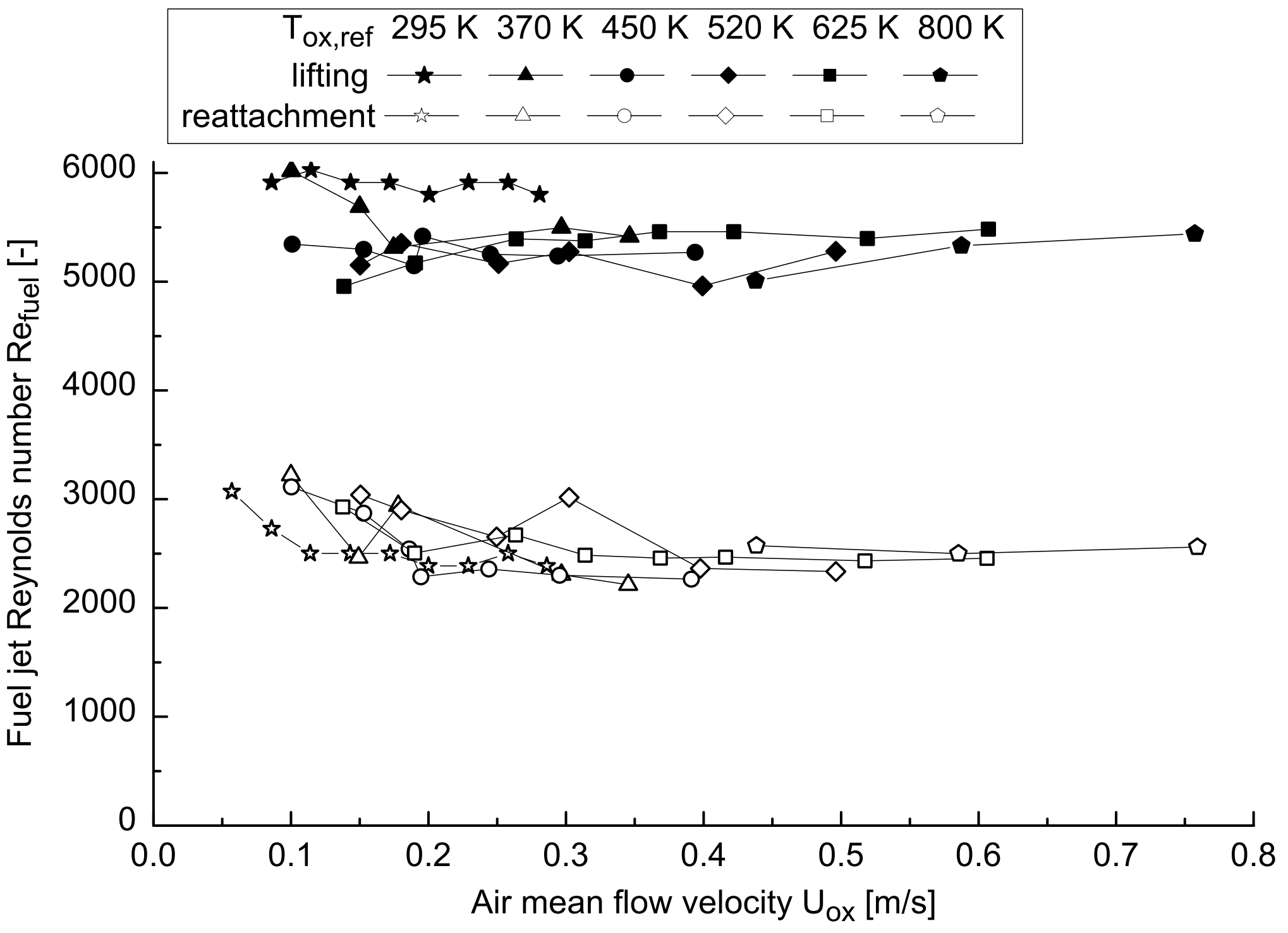




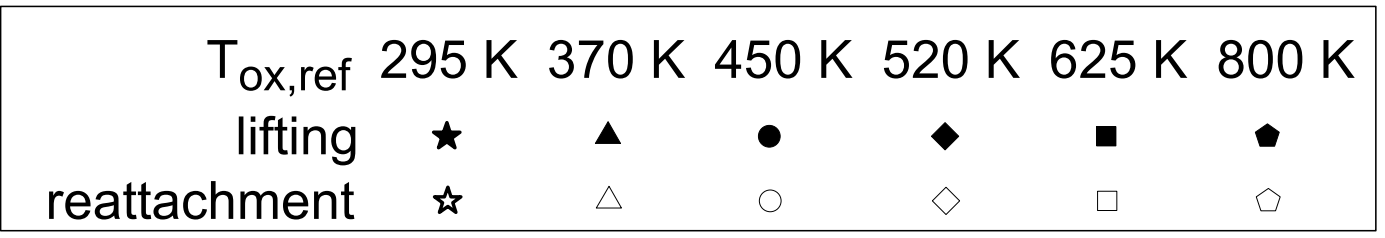

Fuel initial temperature $T_{\text {fuel }}[\mathrm{K}]$

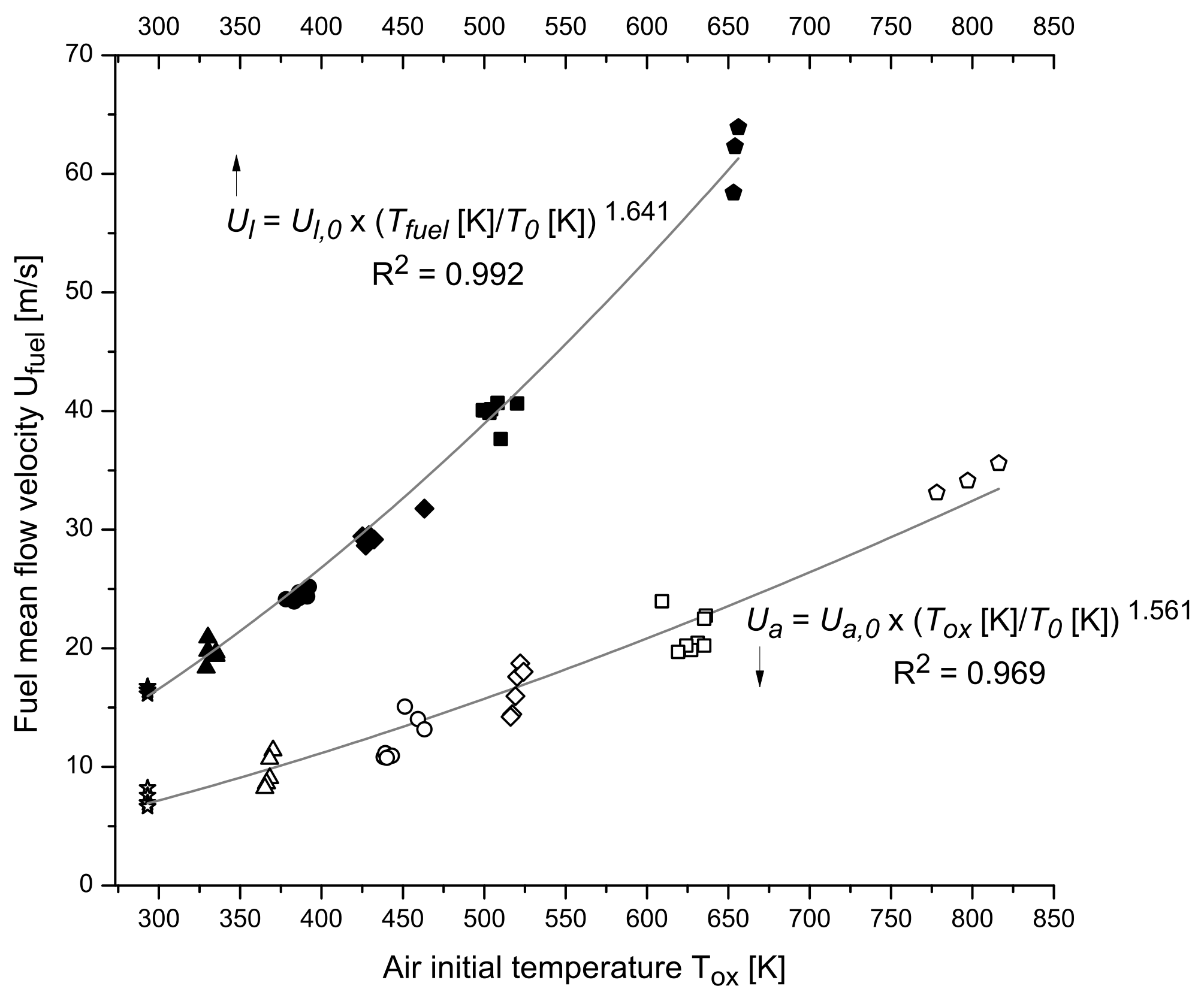


Fuel initial temperature $T_{\text {fuel }}[\mathrm{K}]$

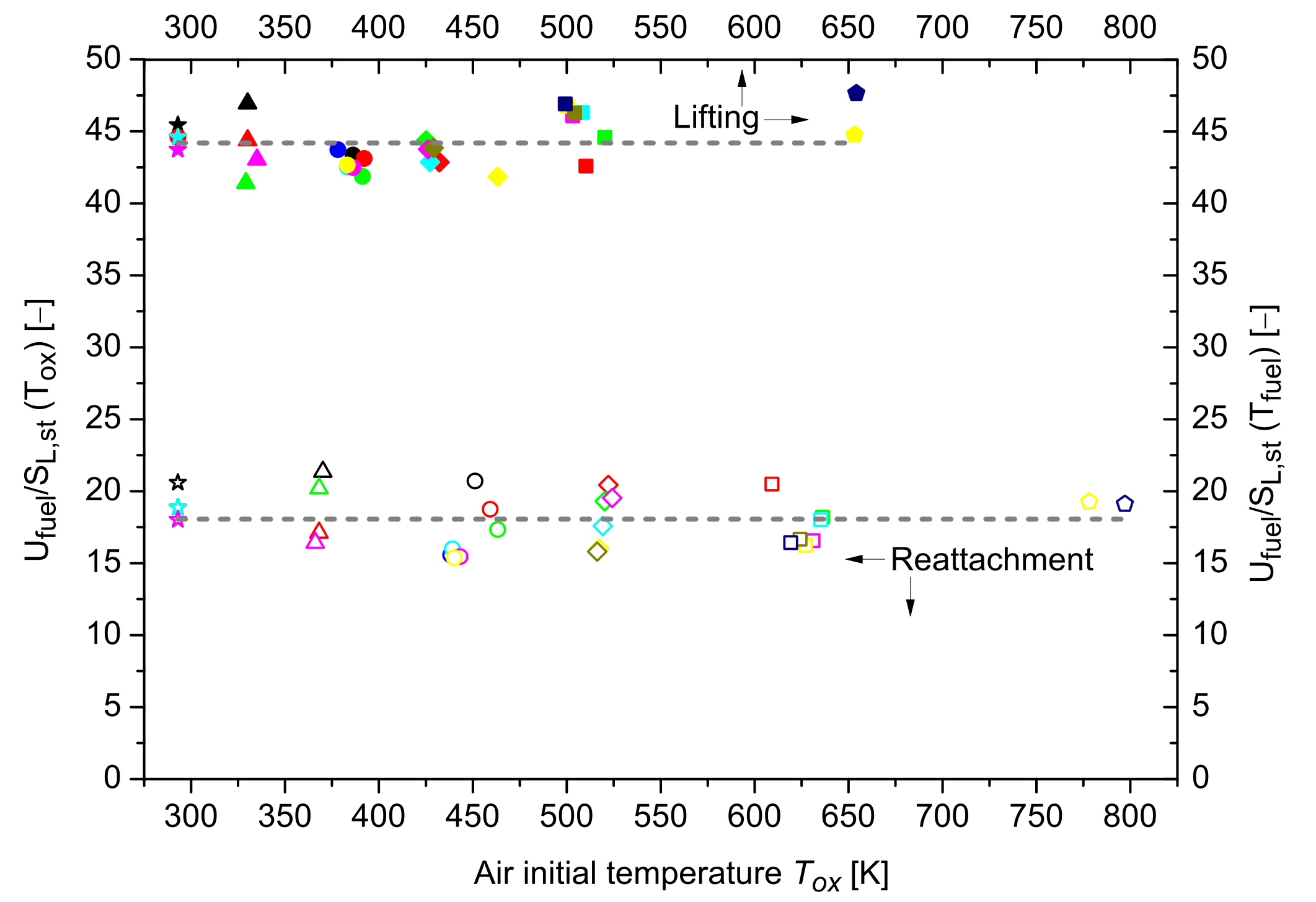


$T_{\text {ox,ref }} 295 \mathrm{~K} \quad 370 \mathrm{~K} \quad 450 \mathrm{~K} \quad 520 \mathrm{~K} \quad 625 \mathrm{~K} \quad 800 \mathrm{~K}$

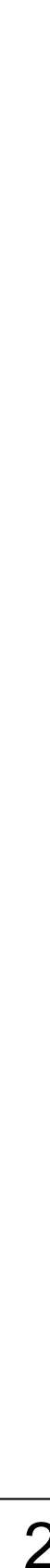

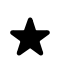

$\Delta$

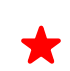

$\star$

$\star$

$+$

$\star$

Lifting

Reattachment
$0.10 \mathrm{~m} / \mathrm{s}$

$0.15 \mathrm{~m} / \mathrm{s}$

$0.18 \mathrm{~m} / \mathrm{s}$

$0.20 \mathrm{~m} / \mathrm{s}$

$0.25 \mathrm{~m} / \mathrm{s}$

$0.30 \mathrm{~m} / \mathrm{s}$

$0.40 \mathrm{~m} / \mathrm{s}$

$0.50 \mathrm{~m} / \mathrm{s}$

$0.60 \mathrm{~m} / \mathrm{s}$

$U_{\text {ox }}$ 


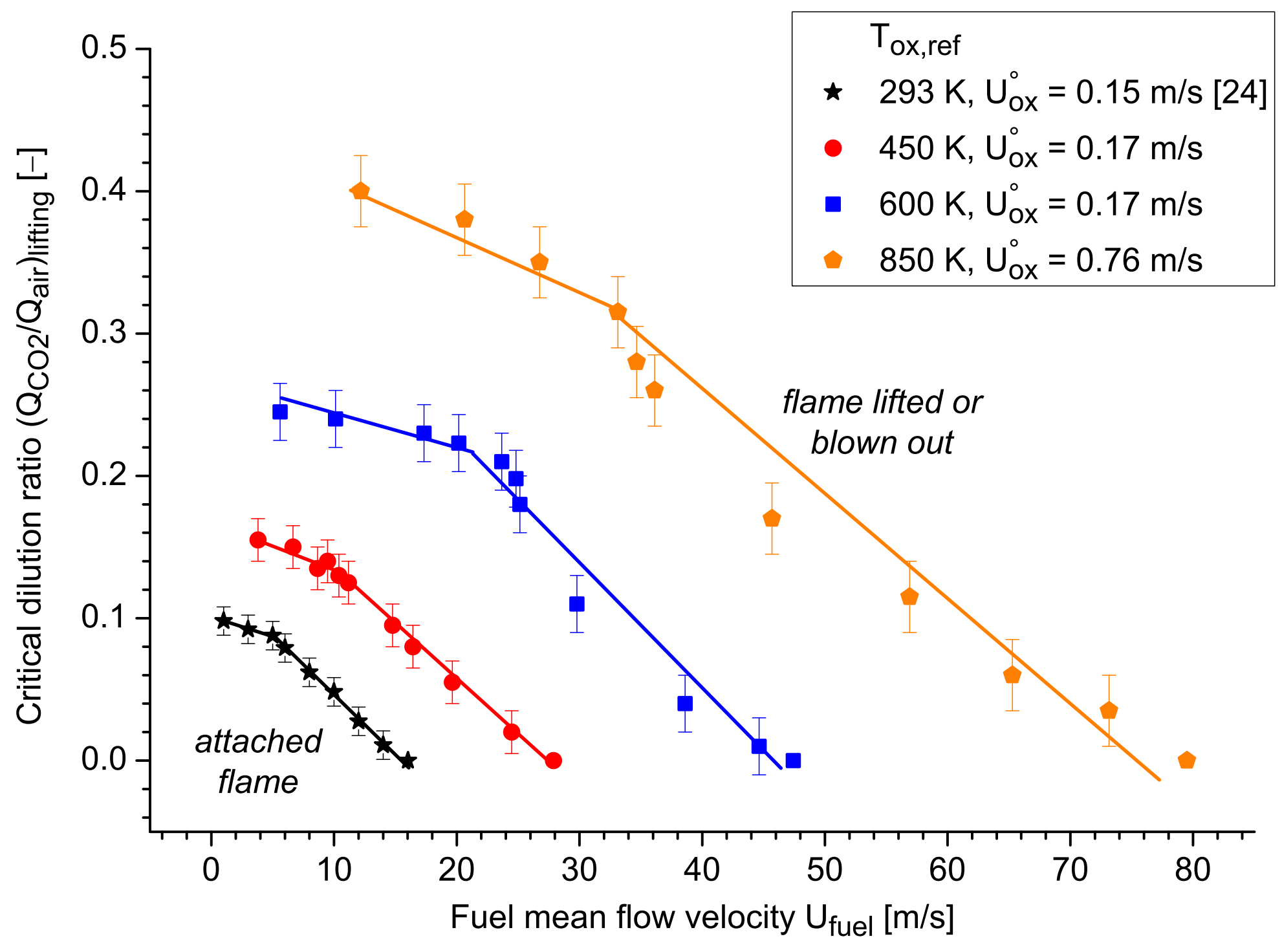




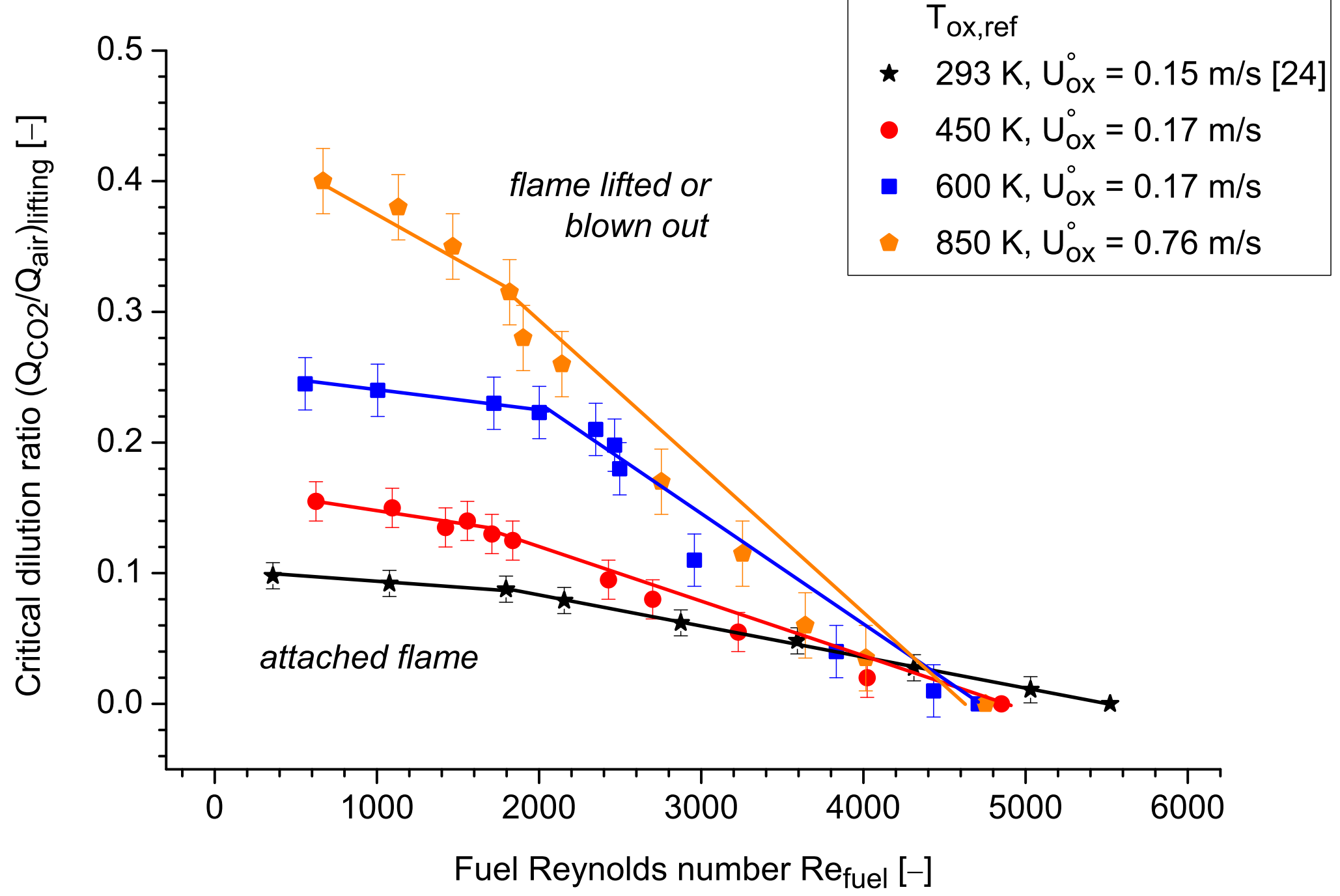

Tox,ref

$293 \mathrm{~K}, \mathrm{U}_{\mathrm{ox}}^{\circ}=0.15 \mathrm{~m} / \mathrm{s}$ [24]

- $450 \mathrm{~K}, \mathrm{U}_{\mathrm{ox}}=0.17 \mathrm{~m} / \mathrm{s}$

- $600 \mathrm{~K}, \mathrm{U}_{\mathrm{ox}}^{\circ}=0.17 \mathrm{~m} / \mathrm{s}$

$850 \mathrm{~K}, \mathrm{U}_{\mathrm{ox}}^{\circ}=0.76 \mathrm{~m} / \mathrm{s}$

Fuel Reynolds number $\operatorname{Re}_{\text {fuel }}[-]$ 


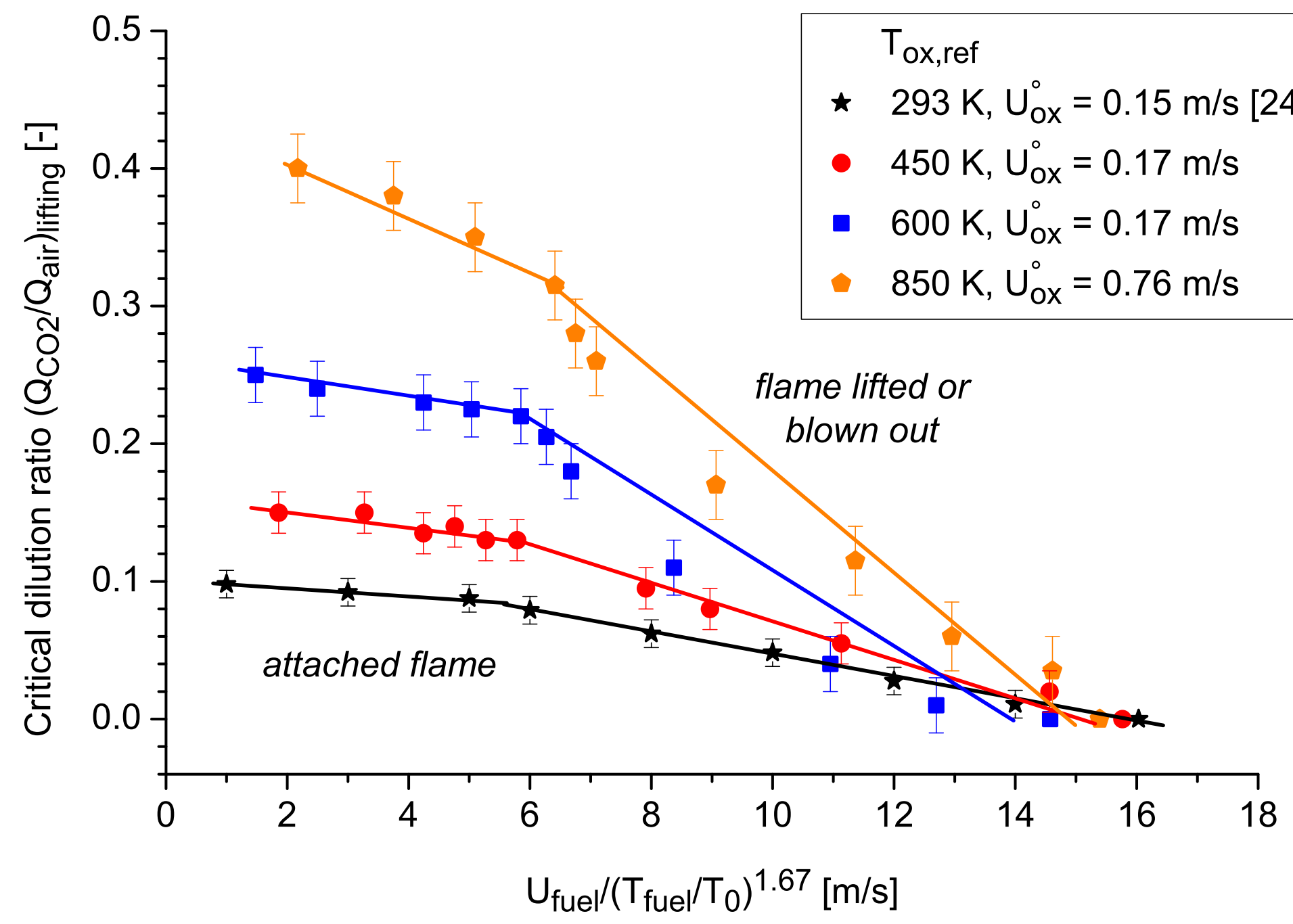




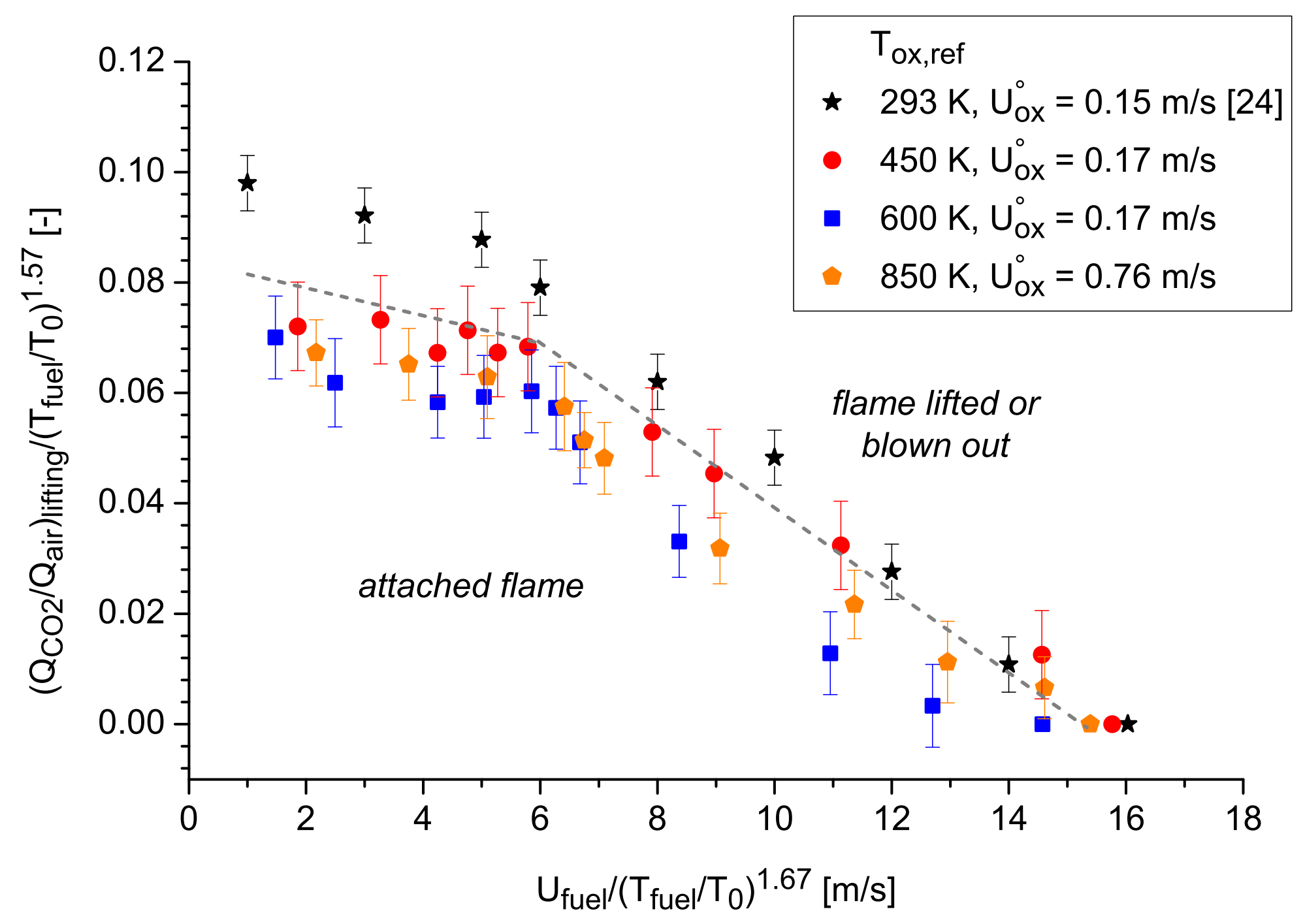




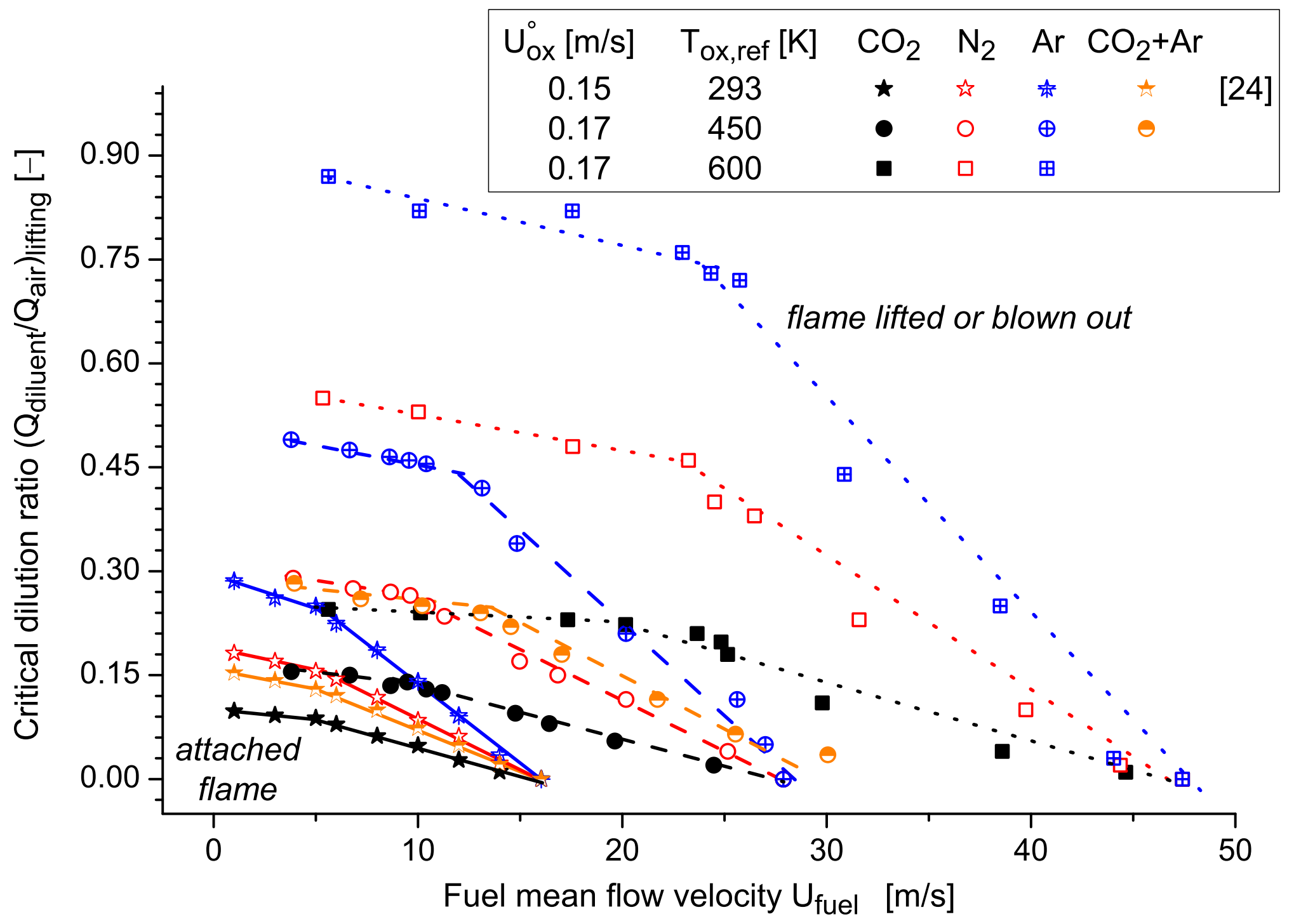




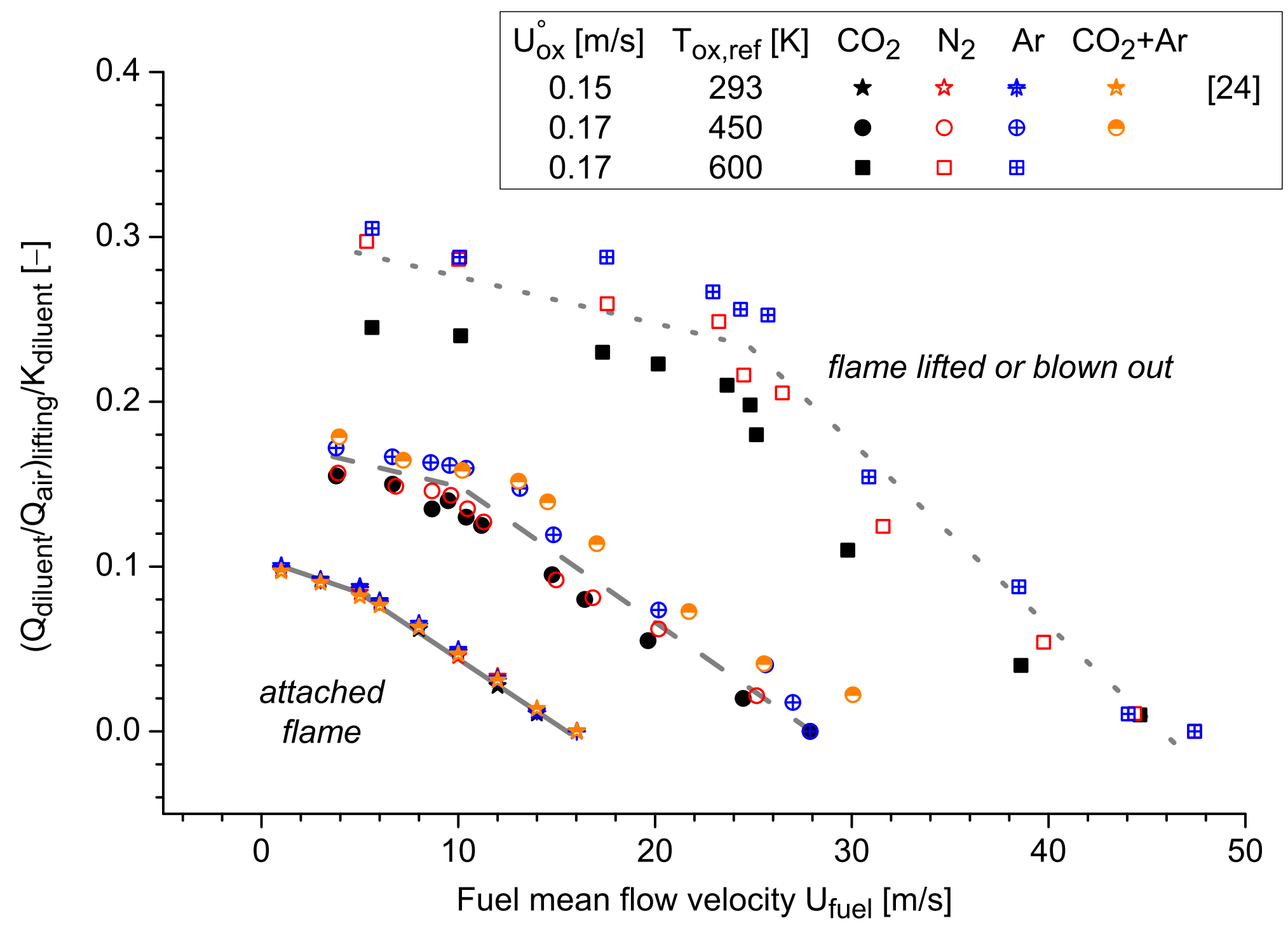




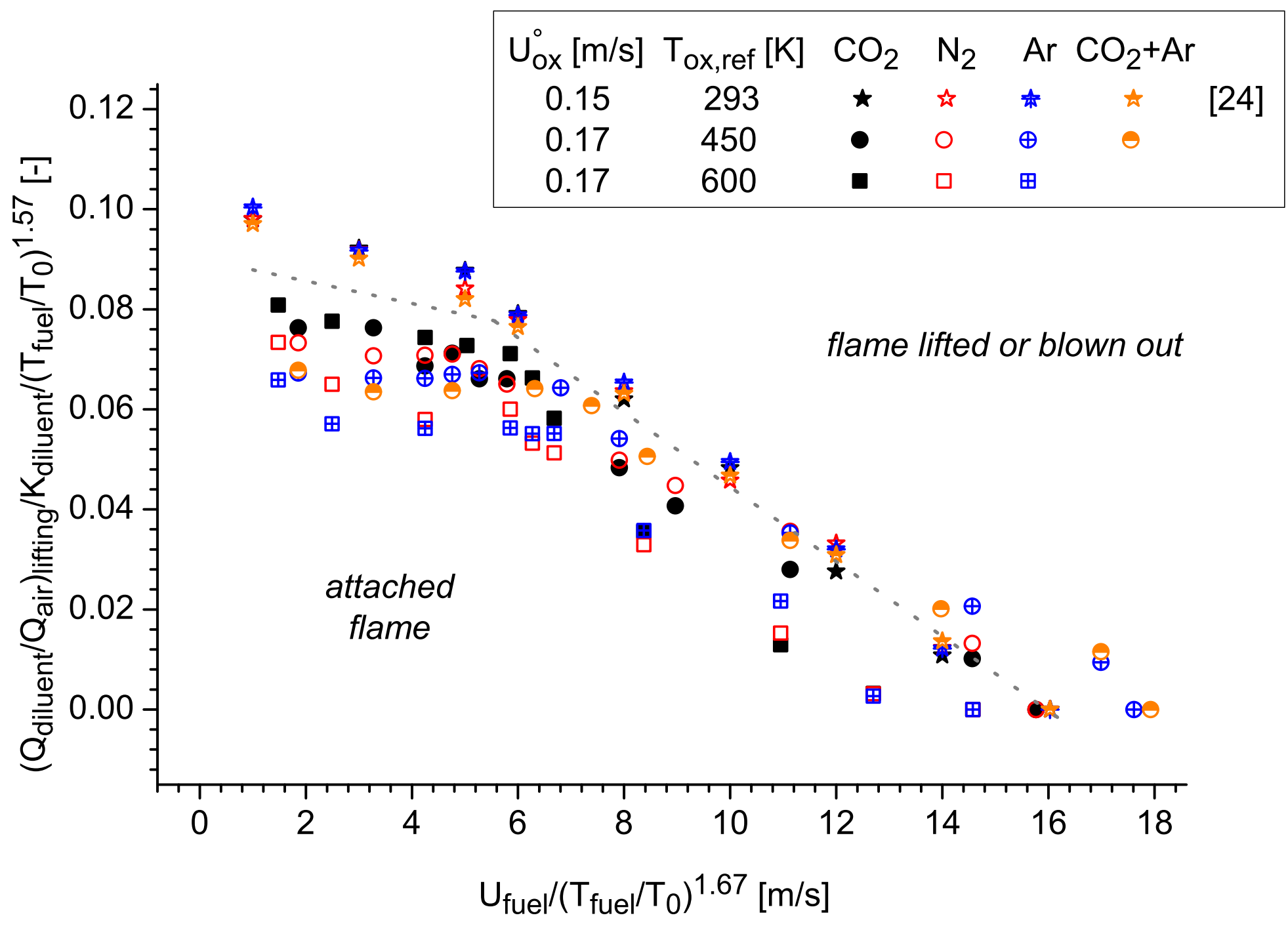




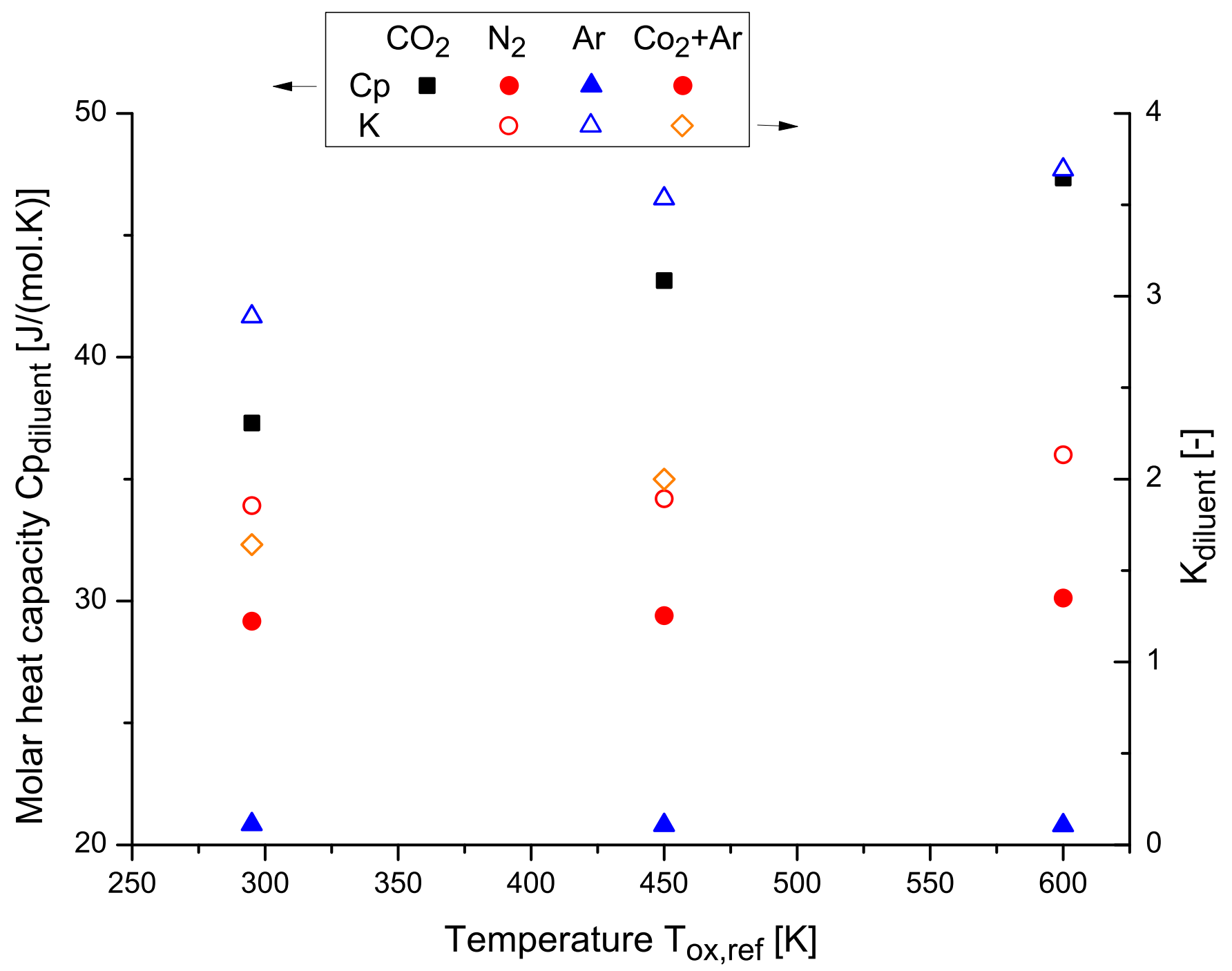

